\title{
Nuclear Energy Return on Energy Investment
}

Fuel Cycle Research \& Development

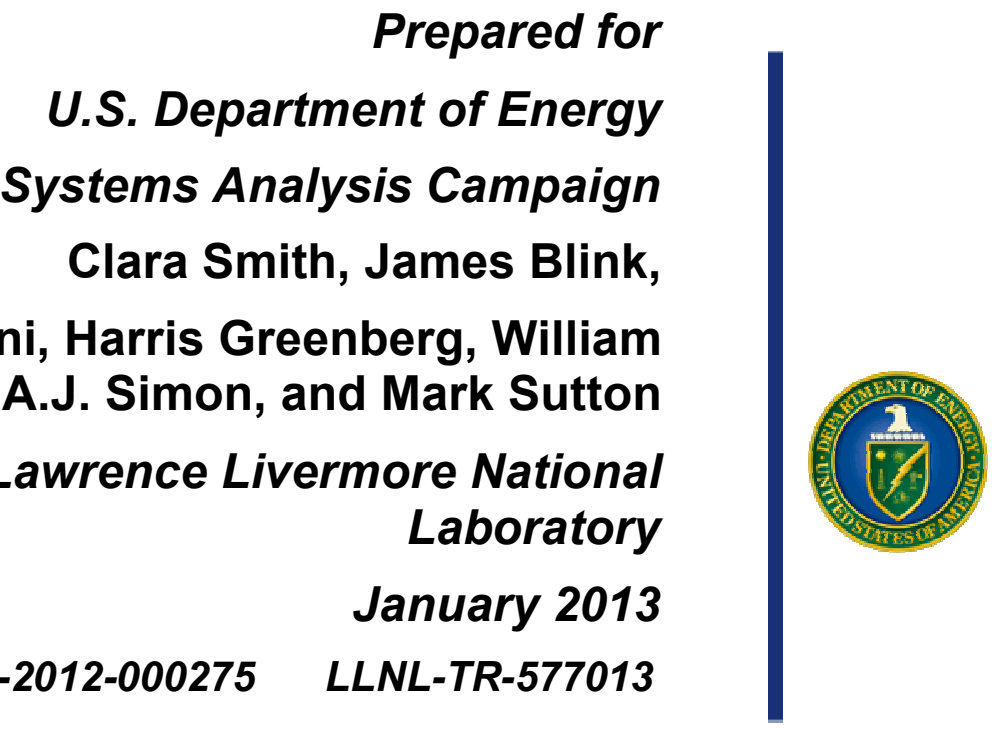

FCR\&D-FCO-2012-000275 LLNL-TR-577013 


\section{DISCLAIMER}

This information was prepared as an account of work sponsored by an agency of the U.S. Government. Neither the U.S. Government nor any agency thereof, nor any of their employees, makes any warranty, expressed or implied, or assumes any legal liability or responsibility for the accuracy, completeness, or usefulness, of any information, apparatus, product, or process disclosed, or represents that its use would not infringe privately owned rights. References herein to any specific commercial product, process, or service by trade name, trade mark, manufacturer, or otherwise, does not necessarily constitute or imply its endorsement, recommendation, or favoring by the U.S. Government or any agency thereof. The views and opinions of authors expressed herein do not necessarily state or reflect those of the U.S. Government or any agency thereof.

This work performed under the auspices of the U.S. Department of Energy by Lawrence Livermore National Laboratory under Contract DE-AC52-07NA27344. 


\section{SUMMARY}

This report provides a methodology and requisite data to assess the potential Energy Return on (Energy) Investment (EROI) for nuclear fuel cycle alternatives, and applies that methodology to an example "oncethrough" fuel cycle using low enrichment uranium (LEU) in conventional light water cooled reactors (LWRs). Within the DOE Office of Nuclear Energy Science and Technology - Fuel Cycle Technologies program, the Fuel Cycle Options Campaign "performs integrating analyses of nuclear energy and fuel cycle systems to inform fuel cycle R\&D, programmatic decisions, strategy formulation, and policy development". Campaign objectives include development of relevant fuel cycle metrics, and development of tools and associated data for analysis of fuel cycle systems. This study represents an extension of a prior evaluation of EROI as a metric for fuel cycle facilities, processes and technologies. That prior study [Simon 2011] addressed the energy return on the addition of fuel recycle to an existing nuclear energy system. Limited to just the addition of fuel recycle, that study did not include all the energy investments required to create, operate and decommission the underlying nuclear fuel cycle, such as uranium mining, fuel fabrication, reactor construction, and used fuel disposition. This extension of the prior work adds these remaining pieces of the fuel cycle to provide a basic evaluation framework and initial data to enable evaluation of EROI for nuclear energy in general. It is intended as a basis for evaluation of alternative fuel cycle options in the future with the addition of pertinent details for other fuel cycle scenarios.

In the prior work, a spreadsheet tool was constructed for the specific purpose of this energy input/output analysis of nuclear fuel cycle facilities. This tool allows the user to enter the parameters of the nuclear fuel cycle and assumptions about energy use in reprocessing. In the current analysis, energy consumption for an entire nuclear energy enterprise is considered, including facility construction, materials, facility operation, and decommissioning. The analysis tool has been extended to include the entire fuel cycle for a representative scenario of a once-through LWR nuclear energy system. Energy content data have been developed for an initial representation. In many cases where there is a valid range of plausible energy content, the range is discussed and a representative value selected for demonstration of the evaluation methodology. In this analysis, energy produced is the energy output of power reactors within the fuel cycle. The spreadsheet calculates both Primary EROI and Final EROI for the fuel cycle entered. The EROI is the ratio of the output energy divided by the consumed energy.

The intent for this study was to develop the methodology and analysis tool for a complete fuel cycle. It is not the intent of the study to fully explore the wide range of potential energy intensities, or to reconcile the disparate values found in the literature. Representative numbers were used in this demonstration. The methodology and tool do provide a framework for future exploration of the key energy intensity values and for conducting sensitivity studies on specific values, either to assess improved understanding of the values, or to explore the potential for alternative technologies to impact EROI. The Primary and Final Energy EROI values calculated for the representative scenario were $\sim 52$ and 24, respectively. 


\section{CONTENTS}

\section{Table of Contents}

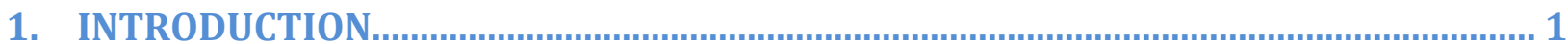

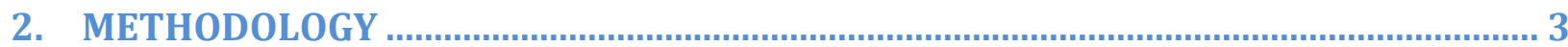

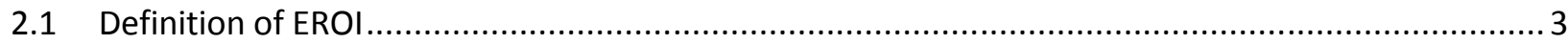

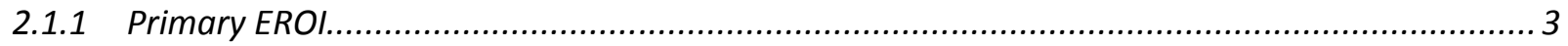

2.1 .2 Final EROI

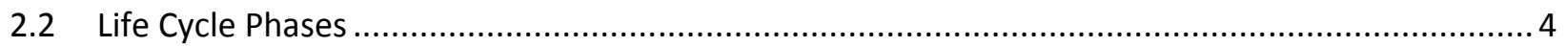

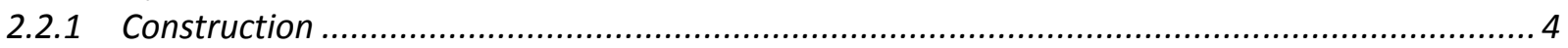

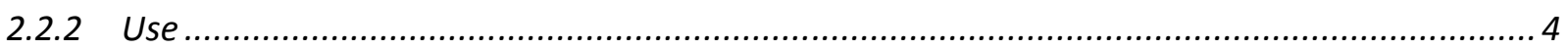

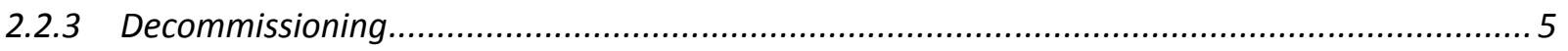

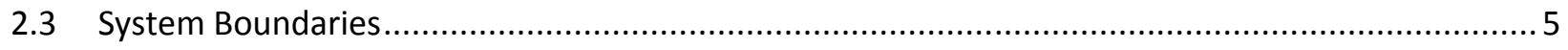

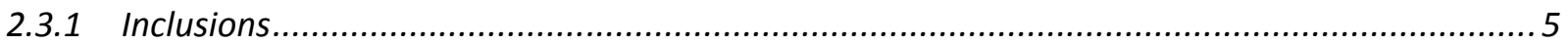

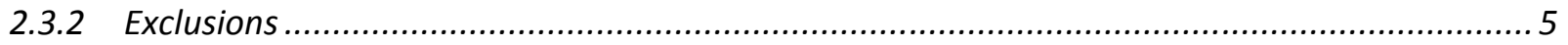

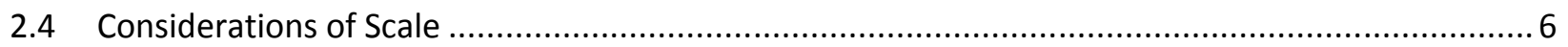

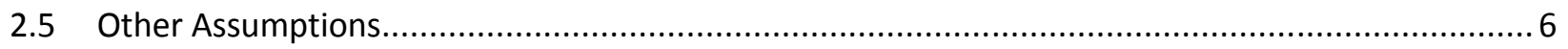

3. FUEL CYCLE DESCRIPTION ............................................................... 7

4. FRONT-END OF THE FUEL CYCLE

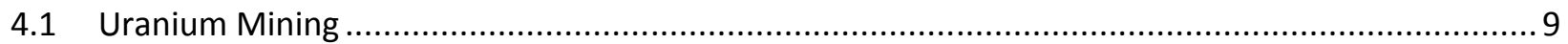

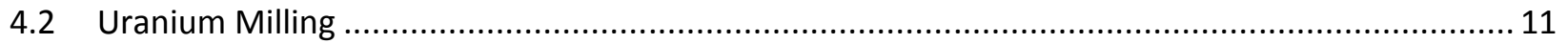

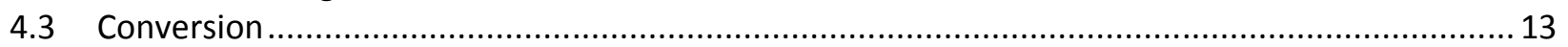

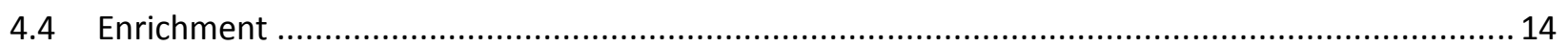

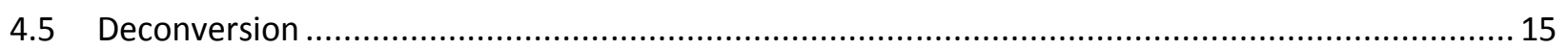

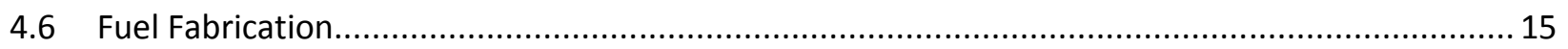

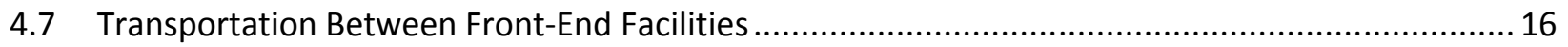

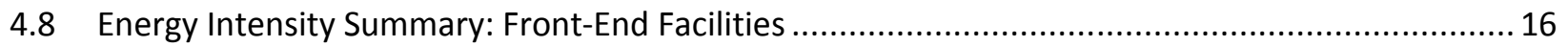

5. REACTOR

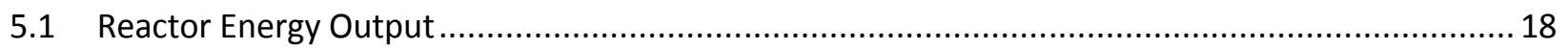

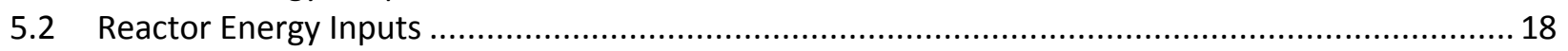

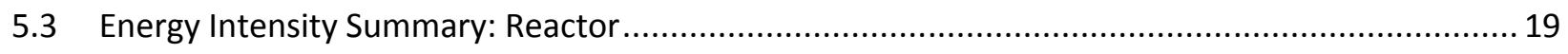

6. BACK-END OF THE FUEL CYCLE

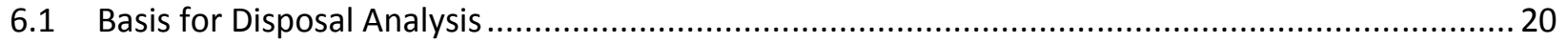

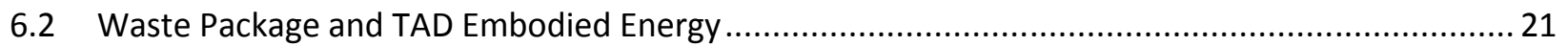

6.3 Repository Construction, Operations, Maintenance, and Closure ............................................. 22

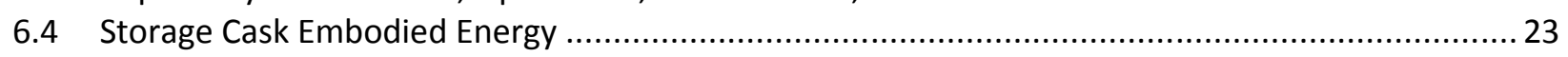

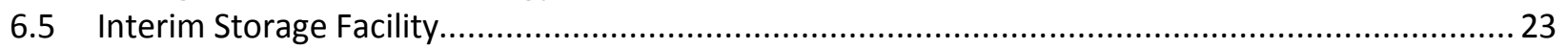

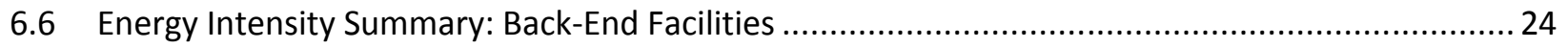

7. ENERGY RETURN ON ENERGY INVESTED

8. SUMMARY AND CONCLUSIONS............................................................................... 28

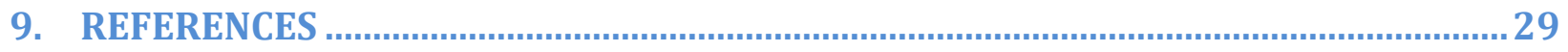


Appendix A: Development of Energy Values ........................................................................... 31

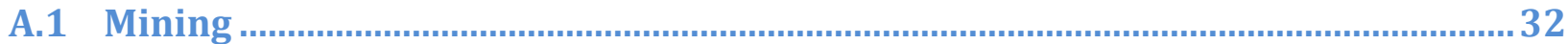

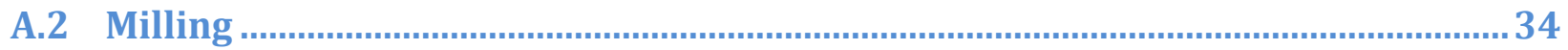

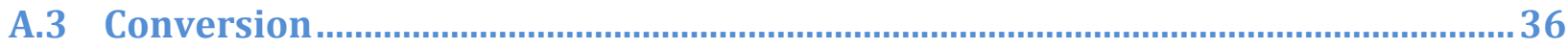

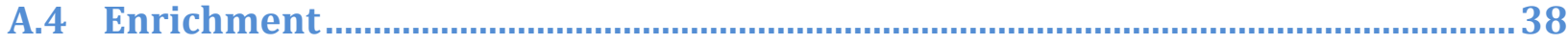

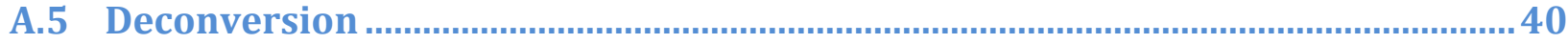

A.6 Fuel Fabrication ................................................................................................................... 41

A.7 Front-End Transportation .............................................................................. 42

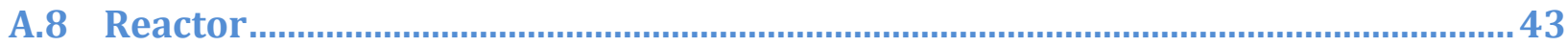

A.9 Waste Packages and Surface Storage Casks ......................................................45

A.10 Geologic Repository and Interim Storage ......................................................... 48 


\section{FIGURES}

Figure 3-1. Material flows associated with one ton of uranium fuel moving through a

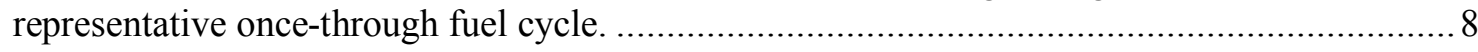

Figure 4-1. Uranium recovery rate as a function of ore grade $\left(\%_{0} \mathrm{U}_{3} \mathrm{O}_{8}\right)$, from Lenzen [2008]............... 10

Figure 7-1. Screen shot of the EROI analysis tool 'Main' page. ....................................................... 25

Figure 7-2. Screen shot of the EROI analysis tool 'Energy Summary' page..........................................26

\section{TABLES}

Table 4.1-1. Reported distribution of uranium mining operations, 1975-2012 (\%).............................9

Table 4.1-2. Final energy intensity for uranium mining [scaled from Rotty, 1975], GJ(e+t)/MTU

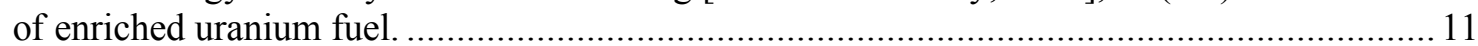

Table 4.1-3. Comparison of energy intensity, GJ per tonne of natural uranium leaving the mill. ............. 12

Table 4.2-1. Final energy intensity for uranium milling [scaled from Rotty, 1975], GJ(e+t)/MTU of enriched uranium fuel.

Table 4.3-1. Energy intensity for uranium conversion, GJ(e+t)/MTU of enriched uranium fuel, this study.

Table 4.4-1. Energy intensities for enrichment, GJ(e+t)/kg-SWU.

Table 4.4-2. Enrichment energy, GJ(e+t) for $1 \mathrm{MTU}$ of enriched uranium fuel, this study.

Table 4.5-1. Energy intensity for uranium deconversion, per MTU of enriched uranium fuel, this study. 15

Table 4.6-1. Energy intensity for fuel fabrication, in GJ/MTU of enriched uranium fuel. 16

Table 4.7-1. Energy intensity for transportation, for this study's representative fuel cycle parameters. 16

Table 4.8-1. Energy intensities for front-end processes, GJ $(e+t) / M T$ enriched uranium fuel 17

Table 5.2-1. Energy intensity for constructing, operating, and demolishing a 1000 MWe PWR, per MTU of enriched uranium fuel. 18

Table 5.3-1. Energy intensities for the reactor, GJ $(\mathrm{e}+\mathrm{t}) / \mathrm{MT}$ enriched uranium fuel. 19

Table 6.1-1. Estimated waste package inventory in a 140,000 MTU commercial spent nuclear fuel repository.

Table 6.2-1. Energy intensity to construct waste packages (including the TAD), GJ(e+t)/MT spent uranium fuel.

Table 6.3-1. Energy intensity to construct, operate, and demolish a repository, GJ(e+t)/MT spent uranium fuel.

Table 6.4-1. Energy intensity to construct aging casks, GJ(e+t)/MT spent uranium fuel.

Table 6.5-1. Energy intensity to construct, operate, and demolish an interim storage facility, $\mathrm{GJ}(\mathrm{e}+\mathrm{t}) / \mathrm{MT}$ spent uranium fuel. 
Table A.1-1. Energy intensity for uranium mining, per tonne of natural uranium, reported in Rotty [1975], using Rotty's units.

Table A.1-2. Energy intensity for uranium mining, per tonne of natural uranium, reported in Rotty [1975], converted to $\mathrm{GJ}(\mathrm{e}+\mathrm{t})$.

Table A.1-3. Energy intensity for uranium mining [scaled from Rotty 1975], GJ(e+t)/tonne of natural uranium with $0.3 \%$ ore grade and $95 \%$ recovery.

Table A.1-4. Energy intensity for uranium mining [scaled from Rotty 1975], GJ(e+t)/MTU of enriched uranium fuel.

Table A.2-1. Energy intensity for uranium milling, per tonne of natural uranium, reported in Rotty [1975], using Rotty's units.

Table A.2-2. Energy intensity for uranium milling, per tonne of natural uranium, reported in Rotty [1975], converted to GJ(e+t).

Table A.2-3. Energy intensity for uranium milling [scaled from Rotty 1975], GJ(e+t)/tonne of natural uranium with $0.3 \%$ ore grade and $95 \%$ recovery.

Table A.2-4 Energy intensity for uranium milling, GJ $(e+t) / M T U$ of enriched uranium fuel .35

Table A.3-1. Energy intensity for uranium conversion, per year, for a dry conversion plant processing 6180 metric tons of natural uranium annually, reported in Rotty [1975], using Rotty's units. .36

Table A.3-2. Energy intensity for uranium conversion, per tonne of natural uranium processed.............. 36

Table A.3-3. Energy intensity for uranium conversion, per tonne of natural uranium processed, from DOE [2012, Tables 5-13 and 5-14], using wet conversion.

Table A.3-4. Energy intensity for uranium conversion, per MT of natural uranium processed, this study.

Table A.3-5. Energy intensity for uranium conversion, per MT of enriched uranium fuel, this study.

Table A.4-1. Energy intensity for uranium enrichment, per SWU of capacity, for a gaseous diffusion plant with 8.75 million $\mathrm{kg}$-SWU capacity and lifetime of $30 \mathrm{yr}$, from Rotty [1975]. 38

Table A.4-2. Rotty's values, converted to GJ. Enrichment energy per SWU of capacity. .38

Table A.4-3. Rotty's values, except for substitution of gas centrifuge dominated direct electrical energy during operation. Enrichment energy per SWU. 39

Table A.4-4. Enrichment energy for 1 MTU of enriched uranium fuel, this study.

Table A.5-1. Energy intensity for uranium deconversion, per MT depleted uranium processed, this study.

Table A.5-2. Energy intensity for uranium deconversion, per MT enriched uranium fuel, this study.

Table A.6-1. Energy intensity for fuel fabrication, per year, for a plant processing 600 MT of enriched uranium fuel annually, reported in Rotty [1975], using Rotty's units.

Table A.6-2. Energy intensity for fuel fabrication, in GJ/MTU of enriched uranium fuel. 41

Table A.7-1. Energy intensity for transportation, from Schneider [2010] .42 
Table A.7-2. Energy intensity for transportation, for this study's representative fuel cycle parameters.

Table A.8-1. Energy output for a 1000 MWe PWR with 50 year lifetime, 90\% capacity factor, $33 \%$ thermal efficiency, and $50 \mathrm{GWd}(\mathrm{th}) / \mathrm{MTU}$ burnup.

Table A.8-2. Annual energy intensity for constructing and operating a 1000 MWe PWR, reported in Rotty [1975], using Rotty's units

Table A.8-3. Lifetime energy intensity for constructing, operating, and demolishing a $1000 \mathrm{MWe}$ PWR.

Table A.8-4. Energy intensity for constructing, operating, and demolishing a 1000 MWe PWR, per MTU of enriched uranium fuel.

Table A.9-1. Estimated waste package inventory in a 140,000 MTU commercial spent nuclear fuel repository. These calculations are based on estimates reported in Hardin [2012].

Table A.9-2. Estimated energy requirements for one waste package. These calculations are based on specifications reported in DOE-RW [2008b] and DOE-RW [1997].

Table A.9-3. Energy intensity to construct waste packages and repackage TADs, GJ(e+t)/MT spent uranium fuel.

Table A.9-4. Estimated energy requirements to fabricate one Aging Cask....................................... 47

Table A.9-5. Energy intensity for aging casks, GJ(e+t)/MT spent uranium fuel. 47

Table A.10-1. Energy intensity needed to construct a geologic repository. Copper and steel energy intensities are from Hammond [2008].

Table A.10-2. Energy intensity needed to operate and monitor a geologic repository........................... 49

Table A.10-3. Energy intensity needed to close a geologic repository. ............................................ 50

Table A.10-4. Energy intensity for constructing, operating, and demolishing a geologic repository, per MTU of enriched uranium fuel. .50

Table A.10-5. Energy intensity needed to construct an interim storage facility. .51

Table A.10-6. Energy intensity needed to operate an interim storage facility. .51

Table A.10-7. Energy intensity needed to close and demolish an interim storage facility. .52

Table A.10-8. Energy intensity needed to construct, operate, and demolish an interim storage facility, per MTU of enriched uranium fuel. 


\section{ACRONYMS}

\begin{tabular}{|c|c|}
\hline BTU & British Thermal Unit \\
\hline D\&D & Decommissioning and Demolition \\
\hline DU & Depleted Uranium \\
\hline EROI & Energy Return on (Energy) Investment \\
\hline FCT & Fuel Cycle Technologies \\
\hline GJ & Gigajoule \\
\hline $\mathrm{GJ}(\mathrm{e}+\mathrm{t}) / \mathrm{MTU}$ & Gigajoules per metric ton Uranium (electricity \& thermal) \\
\hline $\mathrm{GJ} / \mathrm{t} \mathrm{U} 3 \mathrm{O} 8$ & Gigajoule per tonne U3O8 \\
\hline GWd & Gigawatt-Day \\
\hline GWh & Gigawatt-Hour \\
\hline GWh-e & Gigawatt-Hour (Electric) \\
\hline GWh-th & Gigawatt-Hour (Thermal) \\
\hline GWyr & Gigawatt-Year \\
\hline ISL & In-situ Leaching \\
\hline $\mathrm{kWh}$ & Kilowatt Hour \\
\hline LCA & Life Cycle Analysis \\
\hline LEU & Low enrichment Uranium \\
\hline LWR & Light Water Reactor \\
\hline MMBTU & Million BTU \\
\hline MOX & Mixed Oxide Fuel \\
\hline MTU & Metric tons Uranium (tonnes Uranium) \\
\hline MWe & Megawatt (Electric) \\
\hline MWh & Megawatt-Hour \\
\hline NU & Natural (enrichment) Uranium \\
\hline PJ & Petajoule $(1,000,000$ GJ $)$ \\
\hline RepU & Reprocessed Uranium \\
\hline RepUOX & Reprocessed Uranium Oxide Fuel \\
\hline $\mathrm{R} \& \mathrm{D}$ & Research and Development \\
\hline SFR & Sodium Fast Reactor \\
\hline SNF & Spent Nuclear Fuel \\
\hline SWU & Separative Work Unit \\
\hline tHM & Tons of Heavy Metal \\
\hline $\mathrm{tHM} / \mathrm{yr}$ & Tons of Heavy Metal per Year \\
\hline UOX & Uranium Oxide Fuel \\
\hline (e) & Electrical \\
\hline$(\mathrm{t})$ or $(\mathrm{th})$ & Thermal \\
\hline
\end{tabular}





\section{FUEL CYCLE OPTIONS CAMPAIGN}

\section{NUCLEAR ENERGY RETURN ON ENERGY INVESTMENT}

\section{INTRODUCTION}

This report provides a methodology and requisite data to assess the potential Energy Return on (Energy) Investment (EROI) for nuclear fuel cycle alternatives, and applies that methodology to an example 'oncethrough' fuel cycle using low enrichment uranium (LEU) in conventional light water cooled reactors (LWRs). The EROI is the output energy produced divided by the consumed energy invested.

Advanced nuclear energy fuel cycles and enabling technologies are being studied in the United States Department of Energy - Office of Nuclear Energy (USDOE-NE) Fuel Cycle Technologies (FCT) Research and Development Program. The FCT program is chartered in the Nuclear Energy Research and Development Roadmap [DOE-NE 2010] to develop technologies to "enable sustainable fuel cycles" (DOE-NE Objective \#3). This includes technology research and development (R\&D), exploration of potentially transformational technologies, and development of methods to evaluate the potential benefits to society from advanced fuel cycles. Within the FCT program, the Fuel Cycle Options Campaign "performs integrating analyses of nuclear energy and fuel cycle systems to inform fuel cycle R\&D, programmatic decisions, strategy formulation, and policy development". Campaign objectives include development of relevant fuel cycle metrics, and development of tools and associated data for analysis of fuel cycle systems. This study represents an extension of a prior evaluation of EROI as a metric for fuel cycle facilities, processes, and technologies. That prior study [Simon 2011] addressed the energy return on the addition of fuel recycle to an existing nuclear energy system. Limited to just the addition of fuel recycle, that study did not include all the energy investments required to create, operate and decommission the underlying nuclear fuel cycle, such as uranium mining, fuel fabrication, reactor construction, and used fuel disposition. This extension of the prior work develops these remaining pieces of the fuel cycle to provide a basic evaluation framework and initial data to enable evaluation of EROI for nuclear energy in general. It is intended as a basis for evaluation of alternative fuel cycle options in the future with the addition of pertinent details for other fuel cycle scenarios.

In the prior work [Simon 2011], a spreadsheet tool was constructed for the specific purpose of energy input/output analysis of nuclear fuel cycle facilities. This tool allows the user to enter the parameters of the nuclear fuel cycle and assumptions about energy use in reprocessing. In the current analysis, energy consumption for an entire nuclear energy enterprise is considered, including facility construction, materials, facility operation and decommissioning. The analysis tool has been extended to include the entire fuel cycle for a representative scenario of a once-through LWR nuclear energy system. Energy content data have been developed for an initial representation; however, industrial partners have not participated in development of the energy content data for the front and back ends of the fuel cycle in the present study. The literature (much of it decades old) was used as the source of included energy content data. In many cases where there is a valid range of plausible energy content in the literature, the range is discussed and a representative value selected for demonstration of the evaluation methodology. In this 
analysis, energy produced is the energy output of power reactors within the fuel cycle. The spreadsheet calculates both Primary EROI and Final EROI for the fuel cycle entered.

The intent for this study is to develop the methodology and analysis tool for a complete fuel cycle. It is not the intent of the study to fully explore the wide range of potential energy intensities, or to reconcile the disparate values found in the literature. Representative numbers were used in this demonstration. The methodology and tool provide a framework for future exploration of the key energy intensity values and for conducting sensitivity studies on specific values, either to assess improved understanding of the values, or to explore the potential for alternative technologies to impact EROI.

Energy Return on (Energy) Investment is one of many figures of merit on which investment in a new energy facility or process may be judged. EROI is the ratio of the energy delivered by a facility divided by the energy used to construct, operate and decommission that facility. While EROI is not the only criterion used to make an investment decision, it has been shown that energy systems and supplies must exceed a minimum EROI to be integrated into technologically advanced societies. Furthermore, technological history shows a trend towards higher EROI energy supplies.

EROI calculations have been performed for many components of energy technology: oil wells, wind turbines, photovoltaic modules, biofuels, and nuclear reactors. Such analyses for nuclear energy systems have not been conducted or updated for many years, and this report combined with the prior recycle study [Simon 2011] provides the FCT Program with the ability to evaluate EROI for a wide range of fuel cycle alternatives. 


\section{METHODOLOGY}

The purpose of Life Cycle Analysis (LCA) is to benchmark investments, processes and decisions with respect to their costs and benefits. Many LCA figures-of-merit exist, of which EROI is but one. In this report, a bounded Input/Output analysis is used to calculate EROI for a nuclear energy system. The inputs are composed of the energy investments required in obtaining fuel materials; fabricating fuel; constructing, operating, and dismantling nuclear facilities; and disposing of the used fuel. The energy output is the energy delivered by the nuclear reactors.

A spreadsheet tool was constructed for the specific purpose of this input/output analysis. This tool allows the user to enter the parameters of the nuclear fuel cycle and assumptions about energy use in each process. The spreadsheet calculates Primary EROI and Final EROI as described below. The basic EROI calculation is relatively simple. The complexity is in defining the energy production system to be evaluated, its energy boundaries, and in determining reasonable energy content values for the system components. The fuel cycle system is described in Section 3; the energy content data are described in Sections 4, 5, and 6; and the EROI calculation is provided in Section 7.

\subsection{Definition of EROI}

Even within the sub-discipline of LCA dedicated to energy analysis, multiple definitions for EROI exist. For valid comparisons among fuel cycles and for comparison to other types of energy production systems, it is important to state the EROI definition that is being used. Rotty [1975] did an excellent job of explaining four of these definitions. In this report, two versions of the EROI for nuclear fuel cycle are calculated, Primary EROI and Final EROI.

\subsubsection{Primary EROI}

Primary energy is defined as the heating value of energy taken from the environment at the point where it enters the human-managed energy supply chain. Examples of primary energy carriers include uranium ore, wellhead natural gas and unprocessed biomass.

Primary EROI for a process (such as a nuclear fuel cycle) is the gross sum of the primary energy equivalents of the outputs of the process, divided by the gross sum of the primary energy equivalents of the inputs to the process. Electrical inputs and outputs are tallied as the heat required to generate electricity (assuming the electricity could be generated in a thermal power plant fed by a raw natural resource). For the reactors, the output primary energy is the output electrical energy divided by the thermal efficiency. Fuel inputs and outputs are tallied as the gross inputs to fuel refining processes (generally $100 \%-115 \%$ of the refined product). For the purposes of this analysis, the Primary EROI is defined as:

$$
\text { EROI }_{p}=\frac{\text { HEATING VALUE OF ALL FUELS PRODUCED }}{\text { HEATING VALUE OF NATURAL RESOURCES CONSUMED IN THE FUEL CYCLE }}
$$

Primary EROI places all natural resources on an equivalent basis and tallies the resource "tax" that must be paid in order to access more resources. Primary EROI can be thought of as the output energy divided by the subsidy energy required to construct, operate, and demolish the facilities required to produce the output energy, with all energies being given in the same unit (i.e., for this study, electrical inputs and outputs are converted to thermal based on the thermal efficiency of electricity generation). When the 
purpose of an investment is to produce electricity, this measure of EROI is equivalent to Rotty's " $R_{2}$." Rotty uses electrical units (i.e., converting thermal inputs and outputs to electrical based on the thermal efficiency of electricity generation); the value of the ratio $\left(E^{2} \mathrm{II}_{\mathrm{p}}\right.$ or $\left.\mathrm{R}_{2}\right)$ is the same for the two formulations.

\subsubsection{Final EROI}

Final energy is defined as the heating value of energy when it is delivered to the consumer. Examples of final energy carriers include electricity, distributed natural gas and purchased gasoline.

Final EROI for a process (such as a nuclear fuel cycle) is the gross sum of the final energy delivered by the outputs of the process divided by the gross sum of the final energy equivalents of the inputs to the process. When an input or output is electrical, its electrical value is used directly in the EROI formula. Fuel inputs and outputs are tallied as the refined product energies (without the 10-15\% additional primary energy required consumed in refinement). For the purposes of this analysis, the Final EROI is defined as:

$$
\text { EROI }_{f}=\frac{\text { ELECTRICITY PRODUCED FROM NUCLEAR FUEL }}{\text { SUM OF FINAL ENERGY INPUTS TO CONSTRUCTION, USE, AND DECOMMISSIONING }}
$$

Final EROI treats both electricity and fuels on their intrinsic heating value basis. Final EROI can be thought of as treating electrical energy as being equally desirable as the thermal energy available from refined fossil fuels. This measure of EROI is equivalent to Rotty's " $\mathrm{R}_{3}$." Rotty explained that this ratio $\left(E R O I_{f}\right.$ or $\left.R_{3}\right)$ is particularly appropriate if electrical output is used to produce hydrogen or another synthetic energy carrier with about the same efficiency as the current thermal energy used for these purposes.

\subsection{Life Cycle Phases}

Life cycle analyses of specific products consider the value of inputs and outputs related to three phases of that product's life: Manufacturing, Use, and Disposal. Similarly, the life cycle analysis of a facility (such as a nuclear reactor) considers the Construction, Use, and Decommissioning of that facility.

\subsubsection{Construction}

The construction phase of a facility's life cycle includes both direct energy used in construction as well as energy used to manufacture the major materials of construction. Direct energy used in construction includes inputs such as the diesel fuel that powers excavators and cranes as well as the electricity used to power the onsite offices of the construction and engineering contractors. Manufacturing energy includes, for example, the coal and natural gas used in cement making and the electricity and coke required to manufacture steel.

Construction energy is a one-time investment; the inputs discussed here are added as a lump sum to the denominator of the EROI figure of merit.

\subsubsection{Use}

The use phase of a facility's life cycle includes the direct electricity and fuel inputs to the process being analyzed, as well as (when available and applicable) the indirect energy required to manufacture material 
inputs to the process. Examples of direct inputs are electricity to run pumps and motors, and natural gas to generate process steam. Examples of indirect inputs might be the natural gas required for the manufacture of ammonia, or the petroleum required for the production of a kerosene-based solvent.

The use phase is also where the energy outputs of a facility are produced. In this analysis, electricity is produced. In advanced nuclear fuel cycles, such as those discussed in Simon [2011], various types of reprocessed nuclear fuel are produced.

In this analysis, the energy inputs and outputs are reported based on one metric ton of uranium fuel. Construction, use, and decommissioning and demolition energy are considered over the full lifetime of the process, and the energy requirements for each are apportioned uniformly to the uranium fuel processed during the facility lifetime.

\subsubsection{Decommissioning}

The decommissioning phase of a facility's lifecycle includes the energy required to return the facility's geographic footprint to general use. In the case of a nuclear facility (front-end facility, use facility, or back-end facility), this task includes dismantling the building (and tunnel entrances in the case of a repository) and excavating any contaminated foundations or property. All contaminated equipment, structural elements, and soil must be disposed of responsibly. Energy inputs into this phase of the lifecycle include the diesel fuel required to operate demolition equipment, the natural gas and electricity required to immobilize radioactive waste, and the fuel required to transport contaminated material to a repository.

\subsection{System Boundaries}

As its name input/output life cycle analysis suggests, the products and services that cross the system boundaries define the analysis. Movement of the system boundary (to include costs or benefits further up or down the supply chain) is an important part of the development of each analysis. However, results of the analysis can only be interpreted once the boundaries are fixed and clearly described.

This report incorporates estimates of energy inputs from several references, each of which treats its system boundaries somewhat differently.

\subsubsection{Inclusions}

This analysis includes energy supply/use due to:

- Mining, milling, conversion, enrichment, and deconversion of uranium

- Fuel fabrication

- Nuclear reactors

- Used fuel disposition

Energy needed for operation of nuclear fuel cycle facilities includes:

- Fossil fuel energy use in construction, operation, and decommissioning

- Electricity use in construction, operation, and decommissioning

- Energy used in the production of concrete and steel for the construction

\subsubsection{Exclusions}

This analysis does not include energy use due to: 
- Transportation of reagents

- Transportation of workers

\subsection{Considerations of Scale}

The primary goal of this report is to build the capability to evaluate the EROI for a 'once-through' nuclear fuel cycle located in the United States. Because the energy content of facilities and processes can vary with scale of the enterprise, the approximate current U.S. nuclear energy capacity is assumed. In addition, this report assumes that current 'best practice' technologies are employed by industry.

\subsection{Other Assumptions}

Unless otherwise stated, calculations in this report use a number of working assumptions to generate representative fuel cycle energy inputs and outputs:

- Thermal power plants operate at 33\% thermal efficiency, and are representative of a Gen-II 1000 Megawatt electric (MWe) LWR.

- Primary energy for fossil-based energy carriers (distributed natural gas, gasoline, diesel) is $110 \%$ of the final energy.

- Use of the more energy efficient centrifuge technology for uranium enrichment, rather than the older gas centrifuge technology, with $0.25 \%$ tails assay

- Unless more specific data are available, decommissioning energy is $\sim 20 \%$ of the energy needed for construction for facilities not highly contaminated, and $\sim 100 \%$ for contaminated facilities (such as the reactor).

- Values for uranium extraction are a mid-range value for the range of existing uranium resources.

- Values for used fuel disposal are a mid-range for a range of potential repository types.

- Energy content values are estimated for facilities (such as mines, enrichment plant, and repository) of typical industrial scale for a large nuclear energy production enterprise. The energy return analysis is scaled to the basis of a ton of enriched uranium fuel flowing through the fuel cycle.

- All values for construction, operation, and decommissioning and demolition are calculated based on lifetime estimates. When using energy requirements reported in the literature for constructing a process, the energy investment is evenly dispersed over the amount of fuel expected to pass through the process over the unit's lifetime. 


\section{FUEL CYCLE DESCRIPTION}

The representative fuel cycle for this evaluation is once-through use of low enrichment uranium (LEU) in large ( $\sim 1000 \mathrm{MWe})$ light-water cooled reactors. This is similar to what is currently deployed in the U.S., with a few additions or variations. Currently, in the U.S., there is very little domestic uranium production, and a significant fraction of the U.S. fuel supply comes from down-blending of excess highenrichment weapons uranium. However, to represent the energy requirements of a complete oncethrough fuel cycle, the extraction and processing of uranium is needed; therefore, representative uranium supply processes are postulated. Similarly, the U.S. does not currently have a repository for disposal of used nuclear fuel. To represent the complete energy requirements for the once-through fuel cycle, such disposal is needed; therefore, a representative interim storage facility and a representative geologic repository are postulated.

For this example analysis, the fuel cycle is divided into three parts:

- Front-End - Production of nuclear fuel, including uranium mining and milling, conversion, enrichment, deconversion, and fuel fabrication

- Reactor - The nuclear reactor that uses fuel to produce electricity

- Back-End - Disposal of used fuel in a geologic repository

Based on the prior EROI analysis [Simon 2011] for the middle portion of fuel cycles that incorporate fuel recycle, this analysis adds the front and back end of a once-through system and removes the recycle portions. The flow of material through the fuel cycle is shown in Figure 3-1. 


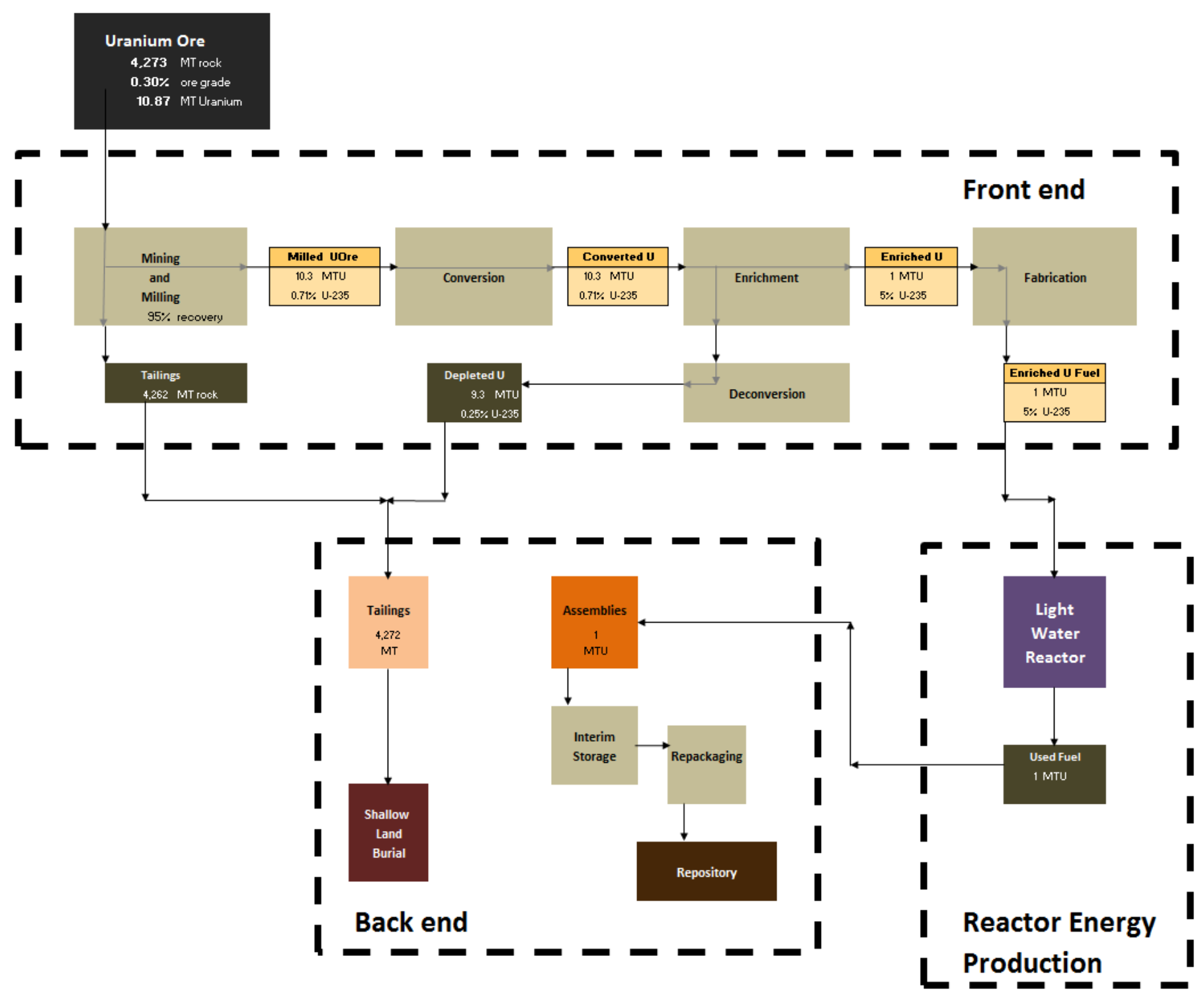

Figure 3-1. Material flows associated with one ton of uranium fuel moving through a representative once-through fuel cycle. 


\section{FRONT-END OF THE FUEL CYCLE}

The front-end of the fuel cycle includes mining of uranium ore, milling of the ore to produce yellowcake, conversion of yellowcake to $\mathrm{UF}_{6}$, enrichment of U-235, and de-conversion of depleted uranium (DU). Sources of information for this analysis include Rotty [1975], Lenzen [2008], and Schneider [2010], in addition to the recent evaluation of environmental impacts, health and safety impacts, and financial costs of the front end of the fuel cycle by Carlson [2012], which includes the evaluation of energy inputs.

The tables in this section are based on the fuel cycle shown in Figure 3-1. The spreadsheet tool includes inputs such as ore grade, recovery fraction, tails enrichment, and fuel enrichment. The spreadsheet adjusts the numbers shown on Figure 3-1 if the user makes changes to the inputs, with the effects being propagated to the EROI calculations.

Decommissioning and Demolition (D\&D) energy intensity is not well known and may vary significantly from case to case. Where data or other estimates are available, values are presented for comparison. In our fuel cycle representation, D\&D energy for industrial type facilities without high-level radioactive material contamination is estimated as $20 \%$ of the construction energy. For facilities with high-level radioactive material contamination, such as reactors, D\&D energy is estimated as $100 \%$ of the construction energy.

\subsection{Uranium Mining}

Uranium is extracted from the ground in numerous countries around the world by four typical mining techniques - open pit, underground excavation, in-situ leaching (ISL), and as a by-product of mining for other metals, particularly rare earth metals (Table 4.1-1). Recovery of uranium from seawater and extraction from phosphate rock are alternative sources of uranium for the fuel cycle, although that is not discussed here.

Table 4.1-1. Reported distribution of uranium mining operations, 1975-2012 (\%).

\begin{tabular}{|l|c|c|c|c|}
\hline \multicolumn{1}{|c|}{ Source } & Open Pit & Underground & In-Situ Leach & $\begin{array}{c}\text { Other (including } \\
\text { co-extraction) }\end{array}$ \\
\hline Rotty [1975] & 59 & 41 & - & - \\
\hline Lenzen [2008] & 30 & 38 & 21 & 11 \\
\hline Red Book [2007] & $26.7^{\mathrm{a}}$ & 36.5 & 27.2 & 9.6 \\
\hline Egger [2011] & 25.7 & $48^{\mathrm{b}}$ & 12.4 & 13.8 \\
\hline World Nuclear [2012] & 17.3 & 30 & 45.2 & $7.5^{\mathrm{c}}$ \\
\hline DOE [2012] & 17.3 & $37.5^{\mathrm{d}}$ & 45.2 & - \\
\hline
\end{tabular}

a includes heap-leaching

${ }^{\mathrm{b}}$ considers Olympic Dam as an underground mine with plans to expand to include an open pit

${ }^{c}$ considers Olympic Dam as a by-product mine rather than underground mine

d considers Olympic Dam as an underground mine only

The energy intensity of uranium mining operations used in this analysis is reported for conventional ore in Table 4.4 of Rotty [1975]. This analysis reports the direct energy inputs for a mixture of open pit and underground mines, common in the United States. Direct energy inputs to mining operations include 
liquid fuel, natural gas, and electricity. Material inputs include ammonium nitrate explosive, water, and construction/fabrication materials (e.g. concrete and steel).

The energy requirements for mining depend not only on the type of mining used to extract uranium, but also on the ore grade, which is defined as the weight-fraction of $\mathrm{U}_{3} \mathrm{O}_{8}$ per unit mass of ore. Lower ore grades also imply lower recovery rates (Fig 4-1).

In some mines, uranium is recovered from lower-grade ores as a by-product or co-extraction product with other minerals, and the energy invested in the mining and milling should be pro-rated among the products. There is no simple consensus method for doing this, and we will not attempt to do so. Instead, we assume a moderately high grade of ore mined on its own (no co-extraction mines). We assumed $0.3 \%$ ore grade (fraction $\mathrm{U}_{3} \mathrm{O}_{8}$ yellowcake, corresponding to $0.2544 \%$ uranium in the ore), with $95 \%$ recovery during mining and milling, as a representative value suitable for evaluating the EROI tool for a complete fuel cycle. In comparison, Rotty [1975] assumed $0.208 \%$ ore grade and $95 \%$ recovery. In reality, recovery is typically closer to $90 \%$ based on the data from Lenzen [2008], and an ore grade of $0.1 \%$ may be more realistic [Schneider 2010 and DOE 2012].

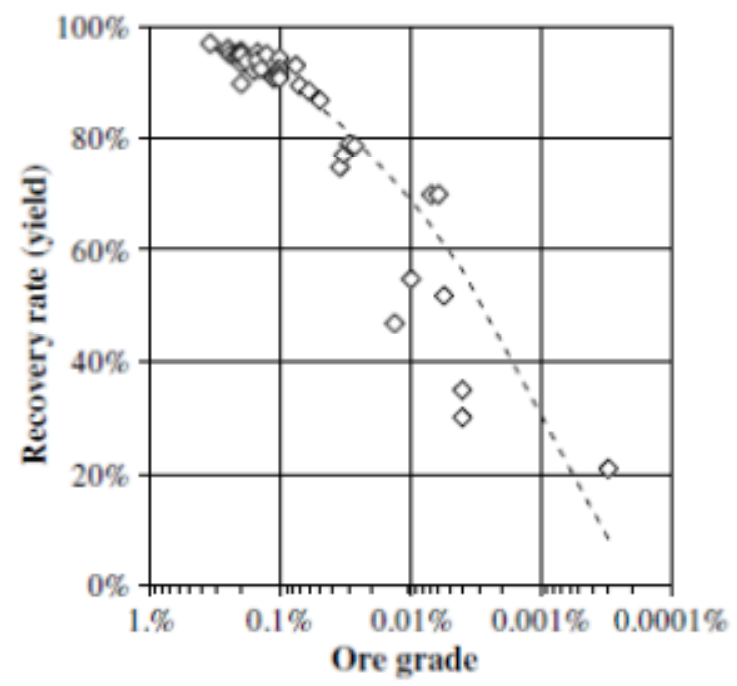

Figure 4-1. Uranium recovery rate as a function of ore grade $\left(\% \mathrm{U}_{3} \mathrm{O}_{8}\right)$, from Lenzen [2008].

Appendix A.1 of this study begins with Rotty's energies for conventional ore in units of MWh(e) and MMBTU, and converts to GJ, all per tonne of uranium leaving the mill. Then the energies are scaled both by user-selectable mining/milling recovery fraction and ore grade. The scaling is implemented in the spreadsheet in a way that the user can input a different ore grade and recovery fraction to explore the sensitivity of the EROI to these parameters (assuming linear scaling is valid). As shown in Figure 3-1 and Appendix A.1, the amount of natural uranium needed to produce 1 metric ton of enriched uranium fuel is 10.87 metric tons, for the user-selectable enrichment, mining/milling recovery fraction, and ore-grade values used in this example. Table A.1-4 of Appendix A.1 multiplies the converted Rotty values, which have been scaled for ore grade and recovery fraction, by 10.3 tonnes natural uranium leaving the mill per tonne of enriched uranium fuel, to obtain mining energies per metric ton of enriched fuel. This table is repeated below as Table 4.1-2, which tracks energy usage separately for construction, operations (direct energy use), and D\&D.

Electrical and thermal (fossil fueled) energy are tracked separately, so that the primary and final EROI ratios can be easily calculated. All the values in Table 4.1-2 are Final Energies. Primary Energies are 
obtained by multiplying electrical energies by $3.03 \mathrm{MWh}-\mathrm{th} / \mathrm{MWh}-\mathrm{e}$, and by multiplying thermal energies by 1.1 GJ-primary/GJ-final, for this study.

Assumptions included in these calculations are as follows: the D\&D energy values are assumed to be $20 \%$ of the construction energy for the mine and there is no energy associated with transportation as the mine is the original location of the uranium.

Table 4.1-2. Final energy intensity for uranium mining [scaled from Rotty, 1975], GJ(e+t)/MTU of enriched uranium fuel.

\begin{tabular}{|c|c|c|c|c|c|}
\hline \multirow[b]{2}{*}{ Phase } & \multirow{2}{*}{$\begin{array}{c}\text { Electrical } \\
\text { GJe }\end{array}$} & \multirow{2}{*}{$\begin{array}{c}\text { Thermal } \\
\text { GJt }\end{array}$} & \multicolumn{2}{|c|}{ Embodied Material } & \multirow{2}{*}{$\begin{array}{c}\text { Total } \\
\text { GJ }\end{array}$} \\
\hline & & & $\begin{array}{c}\text { Electrical } \\
\text { GJe }\end{array}$ & $\begin{array}{c}\text { Thermal } \\
\text { GJt }\end{array}$ & \\
\hline Construction & 41.0 & 853.5 & - & - & 894 \\
\hline Operation & 313 & 1,941 & 145 & 1,201 & 3,600 \\
\hline D\&D & 8.2 & 170.7 & - & - & 179 \\
\hline Total & 362 & 2,965 & 145 & 1,201 & 4,674 \\
\hline
\end{tabular}

Mudd [2008] studied the energy intensity for a number of mines. Table 4.1-3 shows Mudd's results, with the units converted to GJ/MTU. For comparison, the table also shows the results from this study (from Table A.1-3, without the D\&D energy), Rotty [1975], Schneider [2010], and Carlson [2012].

\subsection{Uranium Milling}

Once the uranium-containing ore has been removed from the ground via mining, the uranium is extracted and refined to produce $\mathrm{U}_{3} \mathrm{O}_{8}$ yellowcake. Uranium is extracted from the ore by either an acid process or an alkali process (largely dependent on the ore geochemistry). Direct energy inputs include electrical energy as well as thermal energy from liquid fuel and natural gas. Material inputs depend on whether the acid process or alkali process is used to extract the uranium and can include water, ammonia, sulfuric acid, sodium sulfate, sodium carbonate, and sodium hydroxide.

Energy intensity data for milling is often combined with that of mining, making distinction between the two steps difficult. Rotty [1975] provides information on mining and milling separately, assuming $0.208 \%$ ore grade, a $5 \%$ loss of uranium at the mill (95\% recovery) and $75 \mathrm{lbs}$ of sulfuric acid use per ton of ore mined in the acid milling process. Schneider [2010] further examined uranium supply technologies.

The representative energy intensities for uranium milling from Rotty [1975] are developed in Appendix A.2, similar to the methodology for mining. The values in MWh(e) and MMBTU are first converted to GJ, and then scaled to the $0.3 \%$ ore grade and $95 \%$ recovery fraction used in this study. Finally, the values are multiplied by 10.3 metric tons of natural uranium per metric ton of enriched uranium fuel, producing the values shown in Table 4.2-1. There is no energy associated with transportation as the mine and the milling facility are assumed to be co-located. 
September 1, 2011

Table 4.1-3. Comparison of energy intensity, GJ per tonne of natural uranium leaving the mill.

\begin{tabular}{|c|c|c|c|}
\hline Mine & Type & $\begin{array}{c}\text { Ore Grade, } \\
\quad \% \mathrm{U}_{3} \mathrm{O}_{8}\end{array}$ & GJ/MTU \\
\hline Ranger & Open Pit & $0.28-0.42$ & 225 \\
\hline Olympic Dam & $\begin{array}{l}\text { Underground ( } 20 \% \text { of energy is } \\
\text { shown, due to co-extraction) }\end{array}$ & $0.064-0.114$ & 325 \\
\hline Rossing & Open Pit & $0.034-0.041$ & 420 \\
\hline Cluff Lake & Open Pit & 2.71 & 229 \\
\hline McLean Lake & Open Pit & $1.45-2.29$ & 238 \\
\hline Beverly & In-situ Leaching & 0.18 & 233 \\
\hline Niger & & $0.2-0.5$ & 241 \\
\hline Cameco & & $0.9-4.0$ & 210 \\
\hline \multicolumn{4}{|c|}{ Results from This and Other Studies } \\
\hline This Study (n/i D\&D) & & 0.3 & 435 \\
\hline Rotty [1975] & $\begin{array}{l}\text { 59\% Open Pit, } \\
41 \% \text { Underground }\end{array}$ & 0.208 & 628 \\
\hline Schneider [2010] & $\begin{array}{c}\text { 23\% Open Pit, } \\
\text { 41\% Underground, } \\
36 \% \text { In-situ Leach }\end{array}$ & 0.1 & 332 \\
\hline $\begin{array}{l}\text { Carlson [2012] } \\
\text { (combined mining \& } \\
\text { milling) }\end{array}$ & $\begin{array}{l}\text { 17.3\% Open Pit, } \\
\text { 37.5\% Underground, } \\
\text { 45.2\% In-situ Leach }\end{array}$ & 0.1 & $\begin{array}{c}591 \\
\text { (weighted average of } \\
781,908,255)\end{array}$ \\
\hline
\end{tabular}

Table 4.2-1. Final energy intensity for uranium milling [scaled from Rotty, 1975], GJ(e+t)/MTU of enriched uranium fuel.

\begin{tabular}{|c|c|c|c|c|c|}
\hline \multirow[b]{2}{*}{ Phase } & \multirow{2}{*}{$\begin{array}{c}\text { Electrical } \\
\text { GJe }\end{array}$} & \multirow{2}{*}{$\begin{array}{c}\text { Thermal } \\
\text { GJt }\end{array}$} & \multicolumn{2}{|c|}{ Embodied Material } & \multirow[b]{2}{*}{$\begin{array}{c}\text { Total } \\
\text { GJ }\end{array}$} \\
\hline & & & $\begin{array}{c}\text { Electrical } \\
\text { GJe }\end{array}$ & $\begin{array}{c}\text { Thermal } \\
\text { GJt }\end{array}$ & \\
\hline Construction & 18.3 & 234 & - & - & 252 \\
\hline Operation & 445 & 2,530 & 106 & 1,201 & 4,282 \\
\hline D\&D & 3.66 & 46.8 & - & - & 50.5 \\
\hline Total & 467 & 2,811 & 106 & 1,201 & 4,585 \\
\hline
\end{tabular}




\subsection{Conversion}

Natural uranium is largely U-238, with the fissionable U-235\% comprising only $\sim 0.7 \%$. Prior to use in a nuclear reactor, the uranium must be converted to a form that can be easily enriched. Conversion can be performed using either the "wet" or "dry" processes. In the wet process, the yellowcake is dissolved in nitric acid and extracted in an organic solvent (typically tributyl phosphate, TBP) in hexane or kerosene, and is recovered in the form of uranyl nitrate followed by calcining to form $\mathrm{UO}_{3}$. The dry process involves grinding of the yellowcake and subjecting the particles to reduction under hydrogen to form $\mathrm{UO}_{2}$. Both processes are followed by hydrofluorination to form $\mathrm{UF}_{4}$ using hydrofluoric acid (HF) followed by further fluorination using $\mathrm{F}_{2}$ gas (which is typically produced onsite by electrolysis of $\mathrm{HF}$ ). Direct energy inputs for conversion include electrical energy and natural gas thermal energy. Material inputs depend on whether the wet or dry process is used and may include hydrofluoric acid, barium carbonate, TBP, potassium hydroxide, hexane, kerosene, ammonium sulfate, sodium hydroxide, and ammonia. Thermal energy embodied in the materials must be included in the calculation of energy intensity.

Two sources are used in calculating the energy intensities needed in the conversion process. Rotty [1975] studied the Honeywell Metropolis Works in Metropolis, Illinois, which uses the dry process. Values reported in Carlson [2012] represent energy intensities for the more energy-efficient wet process. Because the construction energy required for the conversion process is more detailed in Rotty [1975], and the dry process and wet process construction requirements are likely similar, Rotty's construction energy values are chosen as representative of the system in this study. The wet process is a more modern and less energy intensive method of uranium conversion; therefore the operation energy intensities reported in Carlson [2012] are used in this study.

Appendix A.3 shows the details of the development of the representative energy intensities for conversion. Table 4.3-1 shows Rotty's results for construction, as well as the Carlson [2012] results for operations. All of the values in the table have been converted from units of GJ/MTU-NU to GJ/MTU fuel by using the ratio of 10.3 MTU NU / MTU enriched uranium fuel.

Assumptions in these calculations are as follows: D\&D energy is assumed to be $20 \%$ of construction energy, and it is estimated that the energy for transporting the milled uranium is due to a travel distance of 1,000 kilometers from the mill to the conversion facility by truck during operations. Thermal energy use (in the form of diesel for transportation) from Schneider [2010, Table 8.6] is shown in Appendix A.7 and in Table 4.3-1.

Table 4.3-1. Energy intensity for uranium conversion, GJ(e+t)/MTU of enriched uranium fuel, this study.

\begin{tabular}{|c|c|c|c|c|c|c|c|}
\hline \multirow[b]{2}{*}{ Phase } & \multirow[b]{2}{*}{$\begin{array}{c}\text { Electrical } \\
\text { GJe }\end{array}$} & \multirow[b]{2}{*}{$\begin{array}{c}\text { Thermal } \\
\text { GJt }\end{array}$} & \multicolumn{3}{|c|}{ Embodied Material } & \multirow[b]{2}{*}{ Transportation } & \multirow[b]{2}{*}{$\begin{array}{c}\text { Total } \\
\text { GJ }\end{array}$} \\
\hline & & & $\begin{array}{c}\text { Electrical } \\
\text { GJe }\end{array}$ & $\begin{array}{c}\text { Thermal } \\
\text { GJt }\end{array}$ & $\begin{array}{c}\text { Inputs } \\
\text { GJt }\end{array}$ & & \\
\hline Construction & 0.237 & 14.9 & 5.72 & 65.9 & - & - & 86.8 \\
\hline Operation & 409 & 1,383 & 334 & 644 & 12.8 & 10.8 & 2,794 \\
\hline D\&D & 0.0474 & 2.99 & - & - & - & - & 3.03 \\
\hline Total & 409 & 1,401 & 340 & 710 & 12.8 & 10.8 & 2,884 \\
\hline
\end{tabular}




\subsection{Enrichment}

Energy requirements for enrichment depend on enrichment level, tail assay, and enrichment process. The enrichment of the product and tails sets the flow rates and determines the separative work units (SWUs) required. For a given amount of SWUs, the energy requirements vary widely by enrichment process. Energy requirements from a number of sources are shown in Table 4.4-1.

Table 4.4-1. Energy intensities for enrichment, GJ(e+t)/kg-SWU.

\begin{tabular}{|c|c|c|}
\hline Source & Process & $\begin{array}{c}\text { GJ }(e+t) \text { per } \\
\text { kg-SWU }\end{array}$ \\
\hline Rotty [1975] & Gaseous Diffusion & 11.0 \\
\hline Lenzen [2008] & Gas Centrifuge & $0.18-1.02$ \\
\hline World Nuclear [2012], URENCO data & Gas Centrifuge & 0.23 \\
\hline Simon [2011], Areva data & Gas Centrifuge & 0.18 \\
\hline This Study & Primarily by Gas Centrifuge & 0.36 \\
\hline
\end{tabular}

Rotty [1975] studied the gaseous diffusion process that was the dominant enrichment technology in the $1970 \mathrm{~s}$, with a resulting annual energy intensity of $11.0 \mathrm{GJ} / \mathrm{SWU}$, of which $10.1 \mathrm{GJ} / \mathrm{SWU}$ is electricity used in the operation of the plant. For comparison, as shown in Table 4.4-1, Lenzen's survey reports electricity consumption from 0.18 to $1.02 \mathrm{GJ} / \mathrm{SWU}$ for gas centrifuge enrichment. This reflects the nominal order of magnitude higher efficiency of the newer process.

The representative energy intensities for uranium enrichment are developed in Appendix A.4. Rotty [1975] used the gaseous diffusion process in his energy estimates, which are dominated by the 2,810 $\mathrm{kWh} / \mathrm{SWU}$ electrical energy required for operation. In this study, we use an intermediate-range value of $0.36 \mathrm{GJ} / \mathrm{SWU}(100 \mathrm{kWh} / \mathrm{SWU})$ as representative of enrichment primarily via centrifuge. Other energy intensities for enrichment are based on the enrichment energy per separative work unit reported in Rotty [1975]. Using the enrichment requirement of 5\% U-235 for the product fuel and $0.25 \%$ U-235 in the tails for a feed of $0.71 \mathrm{U}-235$, a total of 7,932 kg-SWUs are required to process $1 \mathrm{MT}$ of uranium fuel. Using this amount of separative work, the representative energy intensities required in the enrichment process of $\mathrm{UF}_{6}$ are listed in Table 4.4-2 for $1 \mathrm{MT}$ of uranium fuel.

The assumption for these calculations is that converted uranium must travel 1,500 kilometers by rail to the enrichment facility. Thermal energy use (in the form of diesel) from Schneider [2010, Table 8.6] is shown in Appendix A.7, and in Table 4.4-2.

Table 4.4-2. Enrichment energy, GJ(e+t) for 1 MTU of enriched uranium fuel, this study.

\begin{tabular}{|c|c|c|c|c|c|c|}
\hline \multirow[b]{2}{*}{ Phase } & \multirow[b]{2}{*}{$\begin{array}{l}\text { Electrical } \\
\text { GJe }\end{array}$} & \multirow[b]{2}{*}{$\begin{array}{c}\text { Thermal } \\
\text { GJt }\end{array}$} & \multicolumn{2}{|c|}{ Embodied Material } & \multirow[b]{2}{*}{$\begin{array}{c}\text { Transportation } \\
\text { GJt }\end{array}$} & \multirow[b]{2}{*}{$\begin{array}{c}\text { Total } \\
\text { GJ }\end{array}$} \\
\hline & & & $\begin{array}{c}\text { Electrical } \\
\text { GJe }\end{array}$ & $\begin{array}{c}\text { Thermal } \\
\text { GJt }\end{array}$ & & \\
\hline Construction & 9.35 & 589 & 211 & 2,135 & - & 2,945 \\
\hline Operation & 2,856 & 2,808 & 166 & 1,148 & 23 & 7,001 \\
\hline D\&D & 1.87 & 118 & - & - & - & 120 \\
\hline Total & 2,867 & 3,514 & 377 & 3,283 & 23 & 10,065 \\
\hline
\end{tabular}




\subsection{Deconversion}

Appendix A.5 shows the details of the development of the representative energy intensities for deconversion. Because there are no reported values for construction or destruction of a deconversion plant, the construction and decommissioning energy intensities are assumed to be equivalent to those of the Conversion plant listed in Rotty [1975].

Energy intensities for the operation of the deconversion plant are reported in the recent Carlson [2012] study and show a negative value of total final energy (i.e., net energy gain). The energy intensity for deconversion of UF6 tails includes energy costs for lime, ammonia, potassium hydroxide and nitrogen used in the process, but also includes an energy credit for HF, a by-product of the process that can be reused in the conversion step of the fuel cycle. The HF produced during the deconversion process is split into $70 \%$ and $40 \% \mathrm{HF}$ reagents either reused in the process or sold to HF suppliers.

Using the unit energy costs in Carlson [2012], Table 4.5-1 shows the deconversion energy intensities for the representative fuel cycle in Figure 3-1. The values in Table 4.5-1 include the multiplier of 9.33 MT of DU per MT of enriched U fuel. The overall energy total is $24.2 \mathrm{GJ}$ of energy per tonne of enriched uranium fuel. This small value is the result of a credit of 204 GJ per tonne of enriched uranium fuel for recovered HF that can be reused in the conversion step of the process.

Table 4.5-1. Energy intensity for uranium deconversion, per MTU of enriched uranium fuel, this study.

\begin{tabular}{|l|c|c|c|c|c|}
\hline \multicolumn{1}{|c|}{ Phase } & $\begin{array}{c}\text { Electrical } \\
\text { GJe }\end{array}$ & $\begin{array}{c}\text { Thermal } \\
\text { GJt }\end{array}$ & $\begin{array}{c}\text { Embodied } \\
\text { Material, } \\
\text { Electrical } \\
\text { GJe }\end{array}$ & $\begin{array}{c}\text { Embodied } \\
\text { Material, } \\
\text { Thermal } \\
\text { GJt }\end{array}$ & $\begin{array}{c}\text { Total } \\
\text { GJ }\end{array}$ \\
\hline Construction & 0.214 & 13.5 & 5.17 & 59.5 & $\mathbf{7 8 . 4}$ \\
\hline Operation & 108 & 38.9 & -204 & -301 & $\mathbf{- 3 5 8}$ \\
\hline D\&D & 0.0428 & 2.70 & - & - & $\mathbf{2 . 7 4}$ \\
\hline \multicolumn{1}{r|}{ Total } & $\mathbf{1 0 9}$ & $\mathbf{5 5}$ & $\mathbf{- 1 9 9}$ & $\mathbf{- 2 4 2}$ & $\mathbf{- 2 7 7}$ \\
\hline
\end{tabular}

\subsection{Fuel Fabrication}

Fuel fabrication energy requirements from industrial practice are difficult to obtain and compare on a consistent basis, and published values vary over wide ranges. Rotty [1975, Table 7.1] provides values for a plant with 30-year lifetime and annual capacity of 600 MTU of fuel. Appendix A.6 shows the conversion to GJ. Table 4.6-1 shows the resulting energy intensities for the Figure 3-1 fuel cycle.

The assumption for these calculations is that enriched uranium must travel 300 kilometers by rail to the fabrication facility. Thermal energy use (in the form of diesel) from Schneider [2010, Table 8.6] is shown in Appendix A.7.

The primary energy content is from production of zirconium for the cladding. Zircaloy is an alloy of zirconium, with small amounts tin and niobium added for strength and corrosion resistance. The percentages vary by manufacturer, but for a reasonable estimate of the embodied energy, it can be assumed to be pure zirconium, which has an embodied energy of $1610 \mathrm{MJ} / \mathrm{kg}$ [ICE 2008]. Rotty [1975] includes the energy used in the production of zircaloy, however Schneider [2010] does not. The amount of zircaloy cladding needed for 1 MTU of enriched fuel is about $230 \mathrm{~kg}$ (based on $9.5 \mathrm{~mm}$ outer diameter, $0.57 \mathrm{~mm}$ thickness, $3.881 \mathrm{~m}$ length, and 264 rods per assembly containing $0.47 \mathrm{MTU}$ ). 
Table 4.6-1. Energy intensity for fuel fabrication, in GJ/MTU of enriched uranium fuel.

\begin{tabular}{|c|c|c|c|c|c|c|}
\hline \multirow[b]{2}{*}{ Phase } & \multirow[b]{2}{*}{$\begin{array}{c}\text { Electrical } \\
\text { GJe }\end{array}$} & \multirow[b]{2}{*}{$\begin{array}{c}\text { Thermal } \\
\text { GJt }\end{array}$} & \multicolumn{2}{|c|}{ Embodied Material } & \multirow[b]{2}{*}{ Transportation } & \multirow[b]{2}{*}{$\begin{array}{c}\text { Total } \\
\text { GJ }\end{array}$} \\
\hline & & & $\begin{array}{c}\text { Electrical } \\
\text { GJe }\end{array}$ & $\begin{array}{c}\text { Thermal } \\
\text { GJt }\end{array}$ & & \\
\hline Construction & 0.15 & 9.5 & 3.2 & 31.2 & - & 44.1 \\
\hline Operation & 357 & 228 & 723 & 2,438 & 0.9 & 3,746 \\
\hline $\mathrm{D} \& \mathrm{D}$ & 0.03 & 1.9 & - & - & - & 1.93 \\
\hline Total & 357 & 240 & 726 & 2,469 & 0.9 & 3,792 \\
\hline
\end{tabular}

\subsection{Transportation Between Front-End Facilities}

Depending on the location of mining, milling, conversion, enrichment, deconversion, and reactor sites, energy required in transportation between each of these sites should be considered in this evaluation. Mines and mills are typically co-located. Thermal energy use (in the form of diesel) from Schneider [2010, Table 8.6] is shown in Appendix A.7. The appendix places each leg on the basis of 1 MTU of enriched fuel and assumes transportation distances and modes between facilities. The results are shown in Table 4.7-1.

Table 4.7-1. Energy intensity for transportation, for this study's representative fuel cycle parameters.

\begin{tabular}{|l|c|c|c|}
\hline \multicolumn{1}{|c|}{ Route } & Mode & km & $\begin{array}{c}\text { Energy } \\
\text { GJt/MTU }\end{array}$ \\
\hline Mill to Conversion & Truck & 1000 & 10.8 \\
\hline Conversion to Enrichment & Rail & 1500 & 23.4 \\
\hline Enrichment to Fabrication & Rail & 300 & 0.9 \\
\hline Fabrication to PWR & Truck & 1500 & 29.0 \\
\hline Total & & & $\mathbf{6 4 . 1}$ \\
\hline
\end{tabular}

\subsection{Energy Intensity Summary: Front-End Facilities}

The energy intensities of constructing, operating, and decommissioning and demolishing the processes on the front end of the nuclear fuel cycle are summarized in Table 4.8-1. All the energies are Final Energies; the spreadsheet also tracks Primary Energies.

For the fuel cycle shown in Figure 3-1, the energy required to operate the enrichment process $(7,001 \mathrm{GJ}(\mathrm{e}+\mathrm{t}) / \mathrm{MTU})$ is $27 \%$ of the overall total of the front-end energy inputs $(25,724 \mathrm{GJ}(\mathrm{e}+\mathrm{t}) / \mathrm{MTU})$, due to the electrical energy needed to enrich the natural uranium into uranium fuel. The enrichment step (construction, operations, and D\&D) accounts for 39\% of the front-end energy inputs. The operation of the ensemble of facilities accounts for $82 \%$ of the front-end energy inputs, while construction accounts for $17 \%$, and D\&D accounts for only $1 \%$ of the energy inputs. 
Table 4.8-1. Energy intensities for front-end processes, GJ $(\mathrm{e}+\mathrm{t}) / \mathrm{MT}$ enriched uranium fuel

\begin{tabular}{|l|c|c|c|c|}
\hline \multicolumn{1}{|c|}{ Phase } & Construction & Operation & D\&D & Total \\
\hline Mining & 894 & 3,600 & 179 & $\mathbf{4 , 6 7 4}$ \\
\hline Milling & 252 & 4,282 & 50.5 & $\mathbf{4 , 5 8 5}$ \\
\hline Conversion & 86.8 & 2,794 & 3.03 & $\mathbf{2 , 8 8 4}$ \\
\hline Enrichment & 2,945 & 7,001 & 120 & $\mathbf{1 0 , 0 6 5}$ \\
\hline Deconversion & 78.4 & -358 & 2.74 & $\mathbf{- 2 7 7}$ \\
\hline Fabrication & 44.1 & 3,747 & 1.93 & $\mathbf{3 , 7 9 3}$ \\
\hline Total & $\mathbf{4 , 3 0 1}$ & $\mathbf{2 1 , 0 6 6}$ & $\mathbf{3 5 7}$ & $\mathbf{2 5 , 7 2 4}$ \\
\hline
\end{tabular}




\section{REACTOR}

The reactor is where the energy production occurs in the nuclear fuel cycle. Therefore, values for both energy investment and energy production are needed.

\subsection{Reactor Energy Output}

The typical LWR operates on a 12-18 month refueling cycle, with about 1/3 of the core replaced each cycle. The energy production from the fuel varies somewhat by reactor and fuel details, and even for individual fuel rods, and along a single rod - based on the local neutron fluence seen during irradiation. Energy production is typically referenced as a core-average burn-up in terms of Gigawatt days of thermal energy produced per ton of initial heavy metal. For the representative fuel cycle (Figure 3-1) in this study, we assume a burn-up of $50 \mathrm{GWd} / \mathrm{tHM}$, and the spreadsheet the report describes allows this value to be changed for sensitivity studies. The assumed burn-up is larger than for early reactors, is smaller than anticipated in the future, and is a reasonable value for current reactor practice.

Table A.8-1 of Appendix A.8 shows the Primary (thermal) and Final (electrical) output energy for the representative PWR that is the basis of the fuel cycle shown in Figure 3-1. This PWR has 1 GWe output, operates at $90 \%$ capacity factor for 50 years, and has 33\% thermal efficiency. A total of $45 \mathrm{GWyr}(\mathrm{e})$ of Final Energy (136.4 GWyr-th of Primary Energy) is produced over the plant lifetime. Using the burn-up of $50 \mathrm{GWd} / \mathrm{tHM}$, the lifetime fuel requirement is $996.14 \mathrm{MTU}$ of enriched uranium.

On a unit of fuel basis, the PWR produces 4,320,000 GJ(th)/MTU which is equivalent to 1,425,600 GJ(e)/MTU.

\subsection{Reactor Energy Inputs}

The energy requirements for reactor construction and operation are described in both Rotty [1975]. The PWR values from Rotty [1975, Table 8.2] are used in Appendix A.8 to develop the energy intensities in Table 5.2-1. The largest value in this table is for thermal energy of embodied material during the operations phase. This value excludes the fuel itself, which is summarized in Table 4.8-1; rather, this large value is due to chemicals, auxiliary materials, and particularly, refurbishments of plant components [Storm van Leeuwen 2007].

An assumption for these calculations is that fabricated enriched uranium must travel 1,500 kilometers by truck to the light water reactor. Thermal energy use (in the form of diesel) from Schneider [2010, Table 8.6] is shown in Appendix A.7.

Table 5.2-1. Energy intensity for constructing, operating, and demolishing a 1000 MWe PWR, per MTU of enriched uranium fuel.

\begin{tabular}{|c|c|c|c|c|c|c|}
\hline \multirow[b]{2}{*}{ Phase } & \multirow[b]{2}{*}{$\begin{array}{c}\text { Electrical } \\
\text { GJe }\end{array}$} & \multirow[b]{2}{*}{$\begin{array}{c}\text { Thermal } \\
\text { GJt }\end{array}$} & \multicolumn{2}{|c|}{ Embodied Material } & \multirow[b]{2}{*}{ Transportation } & \multirow[b]{2}{*}{$\begin{array}{c}\text { Total } \\
\text { GJ }\end{array}$} \\
\hline & & & $\begin{array}{c}\text { Electrical } \\
\text { GJe }\end{array}$ & $\begin{array}{c}\text { Thermal } \\
\text { GJt }\end{array}$ & & \\
\hline Construction & 31.3 & 1,968 & 709 & 8,180 & & 10,889 \\
\hline Operation & - & 668 & 1,545 & 14,437 & 29.0 & 16,679 \\
\hline $\mathrm{D} \& \mathrm{D}$ & 31.3 & 1,968 & - & - & & 1,999 \\
\hline Total & 62.5 & 4,603 & 2,255 & 22,618 & 29.0 & 29,567 \\
\hline
\end{tabular}




\subsection{Energy Intensity Summary: Reactor}

The energy intensities of constructing, operating, and decommissioning and demolishing the $1 \mathrm{GWe}$ pressurized water reactor are summarized in Table 5.3-1. Output energy is from Table A.8-1. All the energies are Final Energies; the spreadsheet also tracks Primary Energies.

Table 5.3-1. Energy intensities for the reactor, GJ $(\mathrm{e}+\mathrm{t}) / \mathrm{MT}$ enriched uranium fuel.

\begin{tabular}{|l|c|c|c|c|}
\hline \multicolumn{1}{|c|}{ Phase } & Construction & Operation & D\&D & Total \\
\hline Inputs & 10,889 & 16,679 & 1,999 & $\mathbf{2 9 , 5 6 7}$ \\
\hline Output & - & $-1,425,600$ & - & $\mathbf{- 1 , 4 2 5 , 6 0 0}$ \\
\hline \multicolumn{1}{|c|}{ Net Output } & $\mathbf{1 0 , 8 8 9}$ & $\mathbf{- 1 , 4 0 8 , 9 2 1}$ & $\mathbf{1 , 9 9 9}$ & $\mathbf{- 1 , 3 9 6 , 0 3 3}$ \\
\hline
\end{tabular}




\section{BACK-END OF THE FUEL CYCLE}

After the nuclear fuel assemblies have been used to generate power in a once-though fuel cycle at a nuclear power plant, the assemblies are temporarily stored in a spent fuel pool (for at least five years) until they cool down sufficiently to be transferred to on-site dry storage casks. In a complete fuel cycle, they would eventually be transported to a geologic repository for disposal in robust waste packages. Currently, most of the commercial spent nuclear fuel (SNF), on the order of 70,000 metric tons, is stored at utility power plant sites either in fuel pools $(74 \%)$ or dry storage casks $(26 \%)$ [GAO 2012].

The back-end of the fuel cycle shown in Figure 3-1 is assumed to include:

- Transfer of spent nuclear fuel from the utility's fuel pool to shielded dual-purpose (storage and transport) casks. An existing fleet of such casks is already in operation, but more will be needed.

- Transport of these casks to either a centralized interim storage facility for additional aging, or transport to a repository for geologic disposal

- Design and construction of one or more geologic high-level radioactive waste repositories, where the initial construction includes the surface waste handling facilities and some initial access and emplacement tunnels

- Repackaging of the waste into waste packages specifically designed for long-term waste disposal

- Transport of the filled waste packages to the repository for ultimate disposal

- Operations at the repository including:

- Emplacement of waste packages in existing emplacement drifts/boreholes along with simultaneous development (construction) of additional emplacement drifts/boreholes

- At the completion of all emplacement operations, the repository continues to remain open and operates in a "monitoring" mode

- Closure and sealing of the repository

The energy investment in the back-end of the fuel cycle calculated here includes:

- Embodied energy to create the TADs (called repackaging in the spreadsheet tool), waste packages, and storage casks

- Primary energy to construct, operate, and close the interim storage facility and repository facility

- Embodied energy in the interim storage facility and repository facility construction materials

- Energy to transport the SNF to the repository

The energy investment to repackage the waste is accounted for the repackaging step of the ConstructionBack sheet in the spreadsheet tool. Only a single repackaging is assumed as the material moves from reactor to on-site dry storage to centralized storage, and finally to the repository.

\subsection{Basis for Disposal Analysis}

The estimated values in this section are derived from recent studies for geologic disposal alternatives in the U.S. and assume a total waste stream of 140,000 metric tons of commercial spent nuclear fuel from reactors, based on GAO [2012] and Hardin [2012, Table E-1]. The inventory for this basis was derived from Hardin [2012, Table E-1] in Appendix A.9, and is shown in Table 6.1-1, which is identical to Table A.9-1 in the Appendix A.9. The stated values of MTU and assembly counts imply $435.4 \mathrm{~kg}$ of MTU per pressurized water reactor (PWR) assembly and $179.5 \mathrm{~kg}$ of MTU per boiling water reactor (BWR) 
assembly, which are similar values to those found in other references. The capacity for a 21-PWR waste package is 21 PWR fuel assemblies and the capacity for a 44-BWR waste package is 44-BWR fuel assemblies. For some geologic media, a larger quantity of smaller-capacity waste packages would be used, to meet thermal constraints.

Table 6.1-1. Estimated waste package inventory in a 140,000 MTU commercial spent nuclear fuel repository.

\begin{tabular}{|c|c|c|c|}
\hline Type & $\begin{array}{l}\text { Number of } \\
\text { Assemblies }\end{array}$ & $\begin{array}{c}\text { Total Initial Uranium } \\
\text { (MTU) }\end{array}$ & $\begin{array}{c}\text { Number of } \\
\text { Packages }\end{array}$ \\
\hline 21-PWR & 209,000 & 91,000 & 9,952 \\
\hline 44-BWR & 273,000 & 49,000 & 6,205 \\
\hline Total & 482,000 & 140,000 & 16,157 \\
\hline
\end{tabular}

Because the repository energy estimates are the basis for the interim storage facility estimates, the sequence of the detailed sections below is Waste Package, Repository, Interim Storage Cask, and Interim Storage Facility.

\subsection{Waste Package and TAD Embodied Energy}

The waste package design represented in the literature [DOE-RW 2008b] is used in this analysis. The waste packages consist of a Transportation - Aging - Disposal (TAD) canister inside a two-layer waste package. Because the TAD can be introduced into the system at the reactor, at interim storage, or at the repository, its energy values are calculated separately on the spreadsheet tool, in a block called Repackaging.

The TAD energy estimate is based on the difference between 54,250 kilograms, the weight of the full TAD container [DOE-RW 2008b] and 13,816 kilograms, the weight of 21 PWR spent nuclear fuel assemblies [DOE-RW 1997]. For this analysis, stainless steel is assumed to be the dominating TAD material, although the actual basket design also includes carbon steel, borated neutron absorber plates, and aluminum thermal shunts.

The inner canister of the waste package is assumed to be stainless steel for this analysis. The dimensions of the canister are as reported [DOE-RW 2008b] and reproduced in Appendix A.9, with an outer diameter of $1.82 \mathrm{~m}$ and an outer length of $5.51 \mathrm{~m}$. The total volume of the inner canister is $1.79 \mathrm{~m}^{3}$ for a mass of 14,018 kilograms.

The outer canister of the waste package surrounds the inner canister. In this analysis, this canister is assumed to be nickel. The dimensions of the canister are as reported [DOE-RW 2008b] and reproduced in Appendix A.9, with an outer diameter of $1.88 \mathrm{~m}$ and an outer length of $5.72 \mathrm{~m}$. The total volume of the outer canister is $0.98 \mathrm{~m}^{3}$ for a mass of 8,725 kilograms.

The energy intensity to construct the waste package and TAD) are shown in Table 6.2-1, which is identical to Table A.9-3 in Appendix A.9. 
Table 6.2-1. Energy intensity to construct waste packages (including the TAD), GJ(e+t)/MT spent uranium fuel.

\begin{tabular}{|l|c|c|c|c|c|}
\hline \multicolumn{1}{|c|}{ Phase } & \multirow{2}{*}{$\begin{array}{c}\text { Electrical } \\
\text { GJe }\end{array}$} & $\begin{array}{c}\text { Thermal } \\
\text { GJt }\end{array}$ & $\begin{array}{c}\text { Electrical } \\
\text { GJe }\end{array}$ & $\begin{array}{c}\text { Thermal } \\
\text { GJt }\end{array}$ & \multirow{2}{*}{ Total } \\
GJ \\
\hline Construction, TADs & - & - & - & 119 & $\mathbf{1 1 9}$ \\
\hline Construction, WPs & - & - & - & 225 & $\mathbf{2 2 5}$ \\
\hline Operation & - & - & - & - & - \\
\hline D\&D Total & - & - & - & $\mathbf{3 4 4}$ & $\mathbf{3 4 4}$ \\
\hline
\end{tabular}

\subsection{Repository Construction, Operations, Maintenance, and Closure}

The repository energy estimates are based on those developed for the Yucca Mountain repository license application [DOE-RW 2008b] and environmental impact statement [DOE-RW 2002 and DOE-RW 2008a]. The Yucca Mountain repository design was limited to 63,000 MTU of commercial spent fuel, with another 7,000 MTU of high-level waste. The reference repository used for this study is larger, with 140,000 MTU capacity, using the same size waste packages, but with more distance between them, as discussed in Appendix A.10. These changes accommodate other candidate geologic media with different thermal properties and temperature constraints.

Table 6.3-1 shows the energy required to construct, operate, and close the representative repository, which is identical to Table A.10-4 in the Appendix A.10. Transportation for the back end of the fuel cycle is ignored in the present spreadsheet tool, but should be no more than double the $29.0 \mathrm{GJ} / \mathrm{MT}$ shown in Table 5.2-1 for transportation of fresh fuel to the reactor, and that value does not significantly contribute to the overall EROI.

Table 6.3-1. Energy intensity to construct, operate, and demolish a repository, GJ(e+t)/MT spent uranium fuel.

\begin{tabular}{|c|c|c|c|c|}
\hline \multirow[b]{2}{*}{ Phase } & \multirow[b]{2}{*}{$\begin{array}{c}\text { Electrical } \\
\text { GJe }\end{array}$} & \multirow[b]{2}{*}{$\begin{array}{c}\text { Thermal } \\
\text { GJt }\end{array}$} & Embodied Material & \multirow[b]{2}{*}{$\begin{array}{c}\text { Total } \\
\text { GJ }\end{array}$} \\
\hline & & & $\begin{array}{c}\text { Electrical } \\
\text { GJt }\end{array}$ & \\
\hline Construction & 56.5 & 8.7 & 103.1 & 168 \\
\hline Operation & 3,315 & 494 & & 3,809 \\
\hline D\&D & 48.8 & 5.0 & 0.1 & 54 \\
\hline Total & 3,420 & 508 & 103.2 & 4,031 \\
\hline
\end{tabular}




\subsection{Storage Cask Embodied Energy}

Prior to disposal in a geologic repository much of the spent nuclear fuel must be aged either at the utility sites in pools or dry cask storage, or at a centralized interim storage facility. Storage casks will vary in size and construction. For the purposes of this analysis the storage casks are assumed to have a carbon steel shell surrounding by shielding concrete, as described in more detail in Appendix A.9.

The carbon steel canister of the aging cask is 218.5 inches of outer length, 67.7 inches inner diameter, and 2 inches thick. The total volume of the carbon steel canister is $1.80 \mathrm{~m}^{3}$, with a mass of 14,073 kilograms.

The concrete shield surrounds the steel canister in the aging cask. The concrete dimensions are inner diameter of 72.08 inches, inner length of 223.07 inches, and thickness of 2 feet. The total volume of the concrete shield is $35.4 \mathrm{~m}^{3}$, with a mass of 86,567 kilograms.

The energy intensity to construct the aging cask (not including the TAD) is shown in Table 6.4-1, which is identical to Table A.9-5 in Appendix A.9

Table 6.4-1. Energy intensity to construct aging casks, GJ(e+t)/MT spent uranium fuel.

\begin{tabular}{|c|c|c|c|c|c|}
\hline \multirow[b]{2}{*}{ Phase } & \multirow[b]{2}{*}{$\begin{array}{c}\text { Electrical } \\
\text { GJe }\end{array}$} & \multirow[b]{2}{*}{$\begin{array}{c}\text { Thermal } \\
\text { GJt }\end{array}$} & \multicolumn{2}{|c|}{ Embodied Material } & \multirow[b]{2}{*}{$\begin{array}{r}\text { Tota } \\
\text { GJ }\end{array}$} \\
\hline & & & $\begin{array}{c}\text { Electrical } \\
\text { GJe }\end{array}$ & $\begin{array}{c}\text { Thermal } \\
\text { GJt }\end{array}$ & \\
\hline Construction & - & - & - & 18.5 & 18.5 \\
\hline Operation & - & - & - & - & - \\
\hline D\&D & - & - & - & 3.7 & 3.7 \\
\hline Total & - & - & - & 22.2 & 22.2 \\
\hline
\end{tabular}

\subsection{Interim Storage Facility}

The interim storage facility is envisioned as a smaller capacity facility than the repository, with new waste being received from the reactors while older fuel is shipped to the repository. Energies are scaled from the repository numbers, as described in detail in Appendix A.10. Table 6.5-1 shows the energy required to construct, operate, and close the representative repository, which is identical to Table A.10-4 in the Appendix A.10. 
Table 6.5-1. Energy intensity to construct, operate, and demolish an interim storage facility, GJ(e+t)/MT spent uranium fuel.

\begin{tabular}{|c|c|c|c|c|}
\hline Phase & $\begin{array}{c}\text { Electrical } \\
\text { GJe }\end{array}$ & $\begin{array}{c}\text { Thermal } \\
\text { GJt }\end{array}$ & $\begin{array}{c}\text { Embodied Material } \\
\text { GJt }\end{array}$ & $\begin{array}{c}\text { Total } \\
\text { GJ }\end{array}$ \\
\hline Construction & 36 & 5.6 & 6.7 & 48.2 \\
\hline Operation & 64 & 11 & - & 74.3 \\
\hline D\&D & 7.2 & 1.1 & 1.3 & 9.6 \\
\hline Total & 106.8 & 17.4 & 8.0 & 132.1 \\
\hline
\end{tabular}

\subsection{Energy Intensity Summary: Back-End Facilities}

The energy intensities of constructing, operating, and closure of the processes on the back-end of the nuclear fuel cycle are summarized in Table 6.6-1. Shallow land burial, which is not discussed above, includes energy for excavation and backfill of the DU tails. All the energies are Final Energies; the spreadsheet also tracks Primary Energies associated with the cycle.

Table 6.6-1. Energy intensities for back-end processes, GJ(e+t)/MT spent uranium fuel

\begin{tabular}{|l|c|c|c|c|}
\hline \multicolumn{1}{|c|}{ Phase } & Construction & Operation & D\&D & Total \\
\hline Repackaging (TAD canister) & 119 & - & - & $\mathbf{1 1 9}$ \\
\hline Waste Packages & 225 & - & - & $\mathbf{2 2 5}$ \\
\hline Aging Casks & 18.5 & - & 3.7 & $\mathbf{2 2}$ \\
\hline Shallow Land Burial & 231 & - & - & $\mathbf{2 3 1}$ \\
\hline Interim Storage & 48.2 & 74.3 & 9.6 & $\mathbf{1 3 2}$ \\
\hline Repository & 168 & 3,809 & 54 & $\mathbf{4 , 0 3 1}$ \\
\hline Total & $\mathbf{8 1 0}$ & $\mathbf{3 , 8 8 3}$ & $\mathbf{6 7}$ & $\mathbf{4 , 7 6 1}$ \\
\hline
\end{tabular}

The largest contributor by far to the back-end energies is operation of the repository. Examination of the details shows that the energy usage is dominated by the electricity usage during the 50 -year operation phase that includes just-in-time construction of much of the subsurface facilities. DOE-RW [2008a] states that only $30 \%$ of the electrical usage during that period is attributed to construction, yet the annual electrical usage in the monitoring period (after all construction is complete) is only about $7 \%$ of that during the operation period (about 1/10 of the amount attributed to non-construction activities during that later period). Tracing these numbers back through the supporting references to DOE-RW [2008a] could ascertain information that could reduce the operational energy usage for the repository in Table 6.6-1. 


\section{ENERGY RETURN ON ENERGY INVESTED}

The components of the once-through fuel cycle discussed in the preceding sections are included in the EROI analysis tool. The resulting EROI demonstration calculation shows that the analysis tool functions. A screenshot of the 'Main' screen of the analysis tool is shown in Figure 7-1.

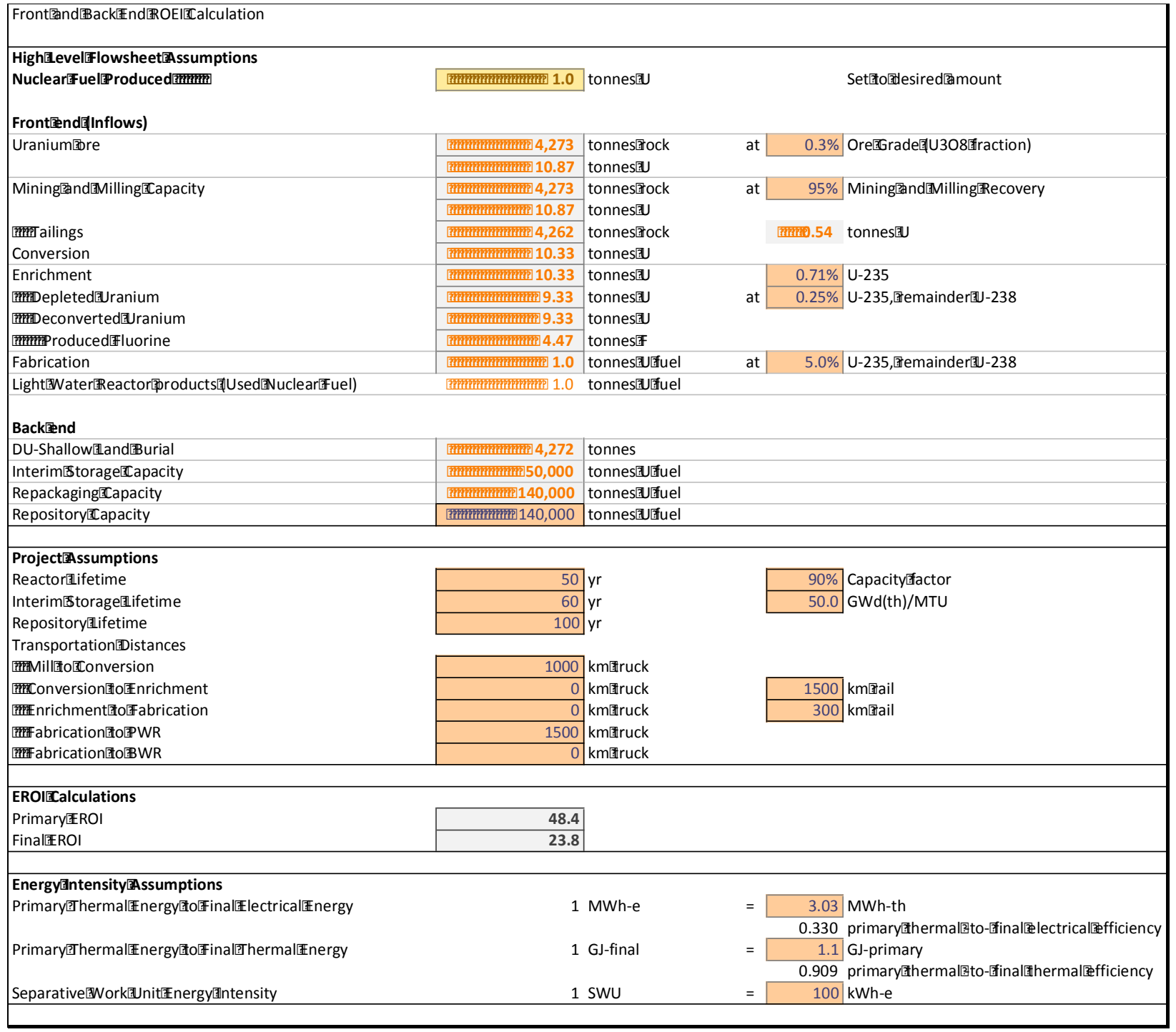

Figure 7-1. Screen shot of the EROI analysis tool 'Main' page.

The resulting energy return on investment values of 48 Primary EROI and 24 Final EROI are shown near the bottom of Figure 7-1. The Energy Summary sheet of the spreadsheet tool is shown in Figure 7-2.

The Use-Front phase is the largest contributor to the energy usage, about triple Construction-Front and more than 5 times Use-Back. Within Use-Front, the LWR is $38 \%$ of the total, followed by Enrichment at $24 \%$ and Mining \& Milling at 19\%. The enrichment values used by Rotty, based on gaseous diffusion, 
are about 18 times those in this study, which uses predominately centrifuge. If the Rotty values were used, the Primary and Final EROI values would drop to 13 and 10, respectively.

\begin{tabular}{|c|c|c|}
\hline & Primary匡ROI & Final㱟OI \\
\hline Energy[Return汿圂nvestment & 48.4 & 23.8 \\
\hline
\end{tabular}

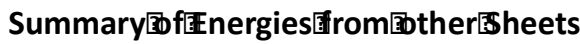
OVERALLTOTAL

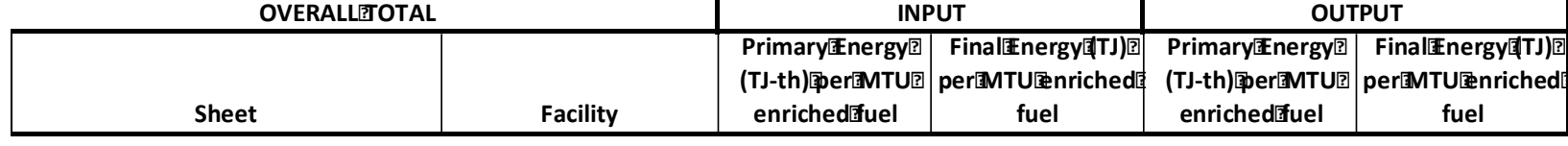

\begin{tabular}{|l|r|r|r|r|}
\hline OVERALLTTOTAL & 89.3 & 59.8 & 4320.0 & 1425.6 \\
\hline
\end{tabular}

\begin{tabular}{|c|c|c|c|c|c|}
\hline Construction-Front & $\sqrt{\text { PHASETOTAL }}$ & 18.7 & 15.2 & & \\
\hline Use-Front & PHASETTOTAL & 56.0 & 37.7 & 4320.0 & 1425.6 \\
\hline Demolition-Front & PHASETTOTAL & 2.7 & 2.4 & & \\
\hline Construction-Back & PHASET?TOTAL & 1.0 & 0.6 & & \\
\hline Use-Back & \begin{tabular}{|l} 
PHASETTOTAL \\
\end{tabular} & 10.8 & 3.9 & & \\
\hline \begin{tabular}{|l} 
Demolition-Back \\
\end{tabular} & \begin{tabular}{|l|} 
PHASETTOTAL \\
\end{tabular} & 0.2 & 0.1 & & \\
\hline
\end{tabular}

TOTALBBYGACILITY

\begin{tabular}{|c|c|c|c|c|c|}
\hline Construction-Front & Mining苜囷illing & 1.376 & 1.147 & & \\
\hline Construction-Front & U民Conversion & 0.107 & 0.087 & & \\
\hline Construction-Front & Enrichment & 3.665 & 2.945 & & \\
\hline Construction-Front & Deconversion & 0.097 & 0.078 & & \\
\hline Construction-Front & Fabrication & 0.055 & 0.044 & & \\
\hline Construction-Front & LWR & 13.408 & 10.889 & & \\
\hline Use-Front & Mining & 10.619 & 7.883 & & \\
\hline Use-Front & UجConversion & 4.508 & 2.794 & & \\
\hline Use-Front & Enrichment & 13.533 & 7.001 & & \\
\hline Use-Front & Deconversion & -0.185 & -0.358 & & \\
\hline Use-Front & Fabrication & 6.206 & 3.747 & & \\
\hline Use-Front & LWR & 21.329 & 16.679 & 4320.0 & 1425.6 \\
\hline Demolition-Front & Mining? & 0.275 & 0.229 & & \\
\hline Demolition-Front & Uxanversion & 0.003 & 0.003 & & \\
\hline Demolition-Front & Enrichment & 0.135 & 0.120 & & \\
\hline Demolition-Front & Deconversion & 0.003 & 0.003 & & \\
\hline Demolition-Front & Fabrication & 0.002 & 0.002 & & \\
\hline Demolition-Front & LWR & 2.259 & 1.999 & & \\
\hline Construction-Back & 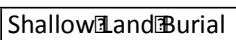 & 0.254 & 0.231 & & \\
\hline Construction-Back & Interim $\$$ torage & 0.152 & 0.067 & & \\
\hline Construction-Back & Repackaging & 0.199 & 0.119 & & \\
\hline Construction-Back & Repository & 0.348 & 0.168 & & \\
\hline Use-Back & Shallow目and值urial & 0.000 & 0.000 & & \\
\hline Use-Back & Interim \$torage & 0.204 & 0.074 & & \\
\hline Use-Back & Repackaging & 0.000 & 0.000 & & \\
\hline Use-Back & Repository & 10.589 & 3.809 & & \\
\hline Demolition-Back & 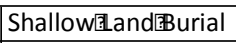 & 0.000 & 0.000 & & \\
\hline Demolition-Back & Interim[torage & 0.030 & 0.013 & & \\
\hline Demolition-Back & Repackaging & 0.000 & 0.000 & & \\
\hline Demolition-Back & Repository & 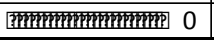 & 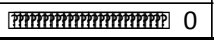 & & \\
\hline
\end{tabular}

Figure 7-2. Screen shot of the EROI analysis tool 'Energy Summary' page. 
Because the intent of this study was to develop the methodology and analysis tool rather than to develop fully defensible energy intensities, reasonable representative values have been used in this demonstration. Therefore the absolute EROI numbers should be considered as analysis examples rather than precise values. 


\section{SUMMARY AND CONCLUSIONS}

This study represents an extension of a prior evaluation of EROI as a metric for fuel cycle facilities, processes and technologies. A prior study [Simon 2011] addressed the energy return on the addition of fuel recycle to an existing nuclear energy system. Limited to just the addition of fuel recycle, that study did not include all the energy investments required to create, operate and decommission the underlying nuclear fuel cycle, such as uranium mining, fuel fabrication, reactor construction and used fuel disposition. This extension of the prior work quantifies these remaining pieces of the fuel cycle to provide a basic evaluation framework and initial data to enable evaluation of EROI for nuclear energy in general. It is intended as a basis for evaluation of alternative fuel cycle options in the future with the addition of pertinent details for other fuel cycle scenarios.

In the prior work, a spreadsheet tool was constructed for the specific purpose of this energy input/output analysis of nuclear fuel cycle facilities. This tool allows the user to enter the parameters of the nuclear fuel cycle and assumptions about energy use in reprocessing. In the current analysis, energy consumption for an entire nuclear energy enterprise is considered, including facility construction, materials, facility operation and decommissioning. The analysis tool has been extended to include the entire fuel cycle for a representative scenario of a once-through LWR nuclear energy system. Energy content data have been developed for an initial representation. In many cases where there is a valid range of plausible energy content, the range is discussed and a representative value selected for demonstration of the evaluation methodology. In this analysis, energy produced is the energy output of power reactors within the fuel cycle. The spreadsheet calculates both Primary EROI and Final EROI for the fuel cycle entered. The EROI is the ratio of the output energy divided by the consumed energy.

The intent for this study was to develop the methodology and analysis tool for a complete fuel cycle. Representative numbers were used in this demonstration, resulting in a Primary EROI of 48 and a Final EROI of 24. It is not the intent of the study to fully explore the wide range of potential energy intensities, or to reconcile the disparate values found in the literature. The methodology and tool do provide a framework for future exploration of the key energy intensity values and for conducting sensitivity studies on specific values, either to assess improved understanding of the values, or to explore the potential for alternative technologies to impact EROI. 


\section{REFERENCES}

BSC 2001. "Site Recommendation Subsurface Layout." ANL-SFS-MG-000001, Rev 00. Las Vegas, Nevada: Bechtel SAIC Company, June 2001.

CARLSON 2012. "Environmental Impacts, Health and Safety Impacts, and Financial Costs of the FrontEnd of the Nuclear Fuel Cycle". B. Carlson, et al. FCRD-FCO-2012-000124, draft in review. September 2012.

DOE-NE 2010. "Nuclear Energy Research and Development Roadmap - Report to Congress". U.S. Department of Energy, Nuclear Energy. April 2010.

DOE-RW 1997. "Integrated Data Base Report-1996: U.S. Spent Nuclear Fuel and Radioactive Waste Inventories, Projections, and Characteristics." U.S. Department of Energy, Office of Environmental Management. DOE-RW-0006, Revision 13. December 1997.

DOE-RW 2002, "YMP Final Environmental Impact Statement for the Site Recommendation". EIS-0250-FEIS-01-2002 Volume I - Impact Analyses - Chapters 1 to 15. 2002.

DOE-RW 2008a. "Yucca Mountain Supplemental Final Environmental Impact Statement for the Site Recommendation". Chapter 4 "Environmental Impacts of Repository Construction, Operation and Monitoring, and Closure". DOE/EIS-0250F-S1 Volume I - Impact Analyses - Chapters 1 to 14. June 2008.

DOE-RW 2008b. "Yucca Mountain Repository SAR". DOE/RW-0573, Rev. 1. November 2008.

GAO 2012. "Accumulating Quantities at Commercial Reactors Present Storage and Other Challenges". GAO-12-797. August 2012.

HAMMOND 2008. Inventory of Carbon \& Energy (ICE). Geoff Hammond and Craig Jones. Version 1.6a. http://perigordvacance.typepad.com/files/inventoryofcarbonandenergy.pdf 2008. Accessed

November 2012.

HARDIN 2012. "Design Concepts/Thermal Load Management (FY11/12) Summary Report. FCRDUFD-2012-00219. Draft in review. August 2012.

ICE 2008. "Inventory of Carbon \& Energy (ICE) Version 1.6a". University of Bath. 2008.

Lenzen 2008. "Life Cycle Energy and Greenhouse Gas Emissions of Nuclear Energy: A Review”. M. Lenzen. Energy Conversion and Management 49 (2008) 2178-2199. Longer version with supporting material available at http://www.isa.org.usyd.edu.au/publications/documents/ISA Nuclear Report.pdf Accessed August, 2011.

MUDD 2008. "Sustainability of Uranium Mining and Milling: Toward Quantifying Resources and EcoEfficiency”. G. M. Mudd and M. Diesendorf. Environmental Science \& Technology, 42, 2624-2630. 2008.

RED BOOK 2007. “Uranium 2007: Resources, Production and Demand”. OECD/International Atomic 
Energy Agency (IAEA)OECD Publishing. doi: 10.1787/uranium-2007-en 2007.

ROTTY 1975"Net Energy from Nuclear Power". R.M. Rotty, A.M. Perry and D.B. Reister. Institute for Energy Analysis, Oak Ridge Associated Universities, IEA-75-3. 1975.

SCHNEIDER 2010. "Measures of the Environmental Footprint of the Front End of the Nuclear Fuel Cycle”. E. Schneider, B. Carlsen, and E. Tavrides. INL Technical Report FCRD-SYSA-2010-000104. 2010.

SIMON 2011. "Energy Return on Investment - Fuel Recycle". A. J. Simon, M. Fratoni, C. Smith, and W. Halsey. Lawrence Livermore National Laboratory, LLNL-TR-497511, FCR\&D-SYSA-2011-000317. August 2011.

STORM van LEEUWEN 2007. "Nuclear Power - The Energy Balance", J. W. Storm van Leeuwen and P. B. Smith. Part F5. www.stormsmith.nl/reports.html Accessed August 2012 (dated December 2007).

WORLD-NUCLEAR 2012. "Energy Analysis of Power Systems", World Nuclear Association. http://www.world-nuclear.org/info/infl 1.html Accessed March 2012. 


\section{APPENDIX A: DEVELOPMENT OF ENERGY VALUES}




\section{A.1 Mining}

Rotty [1975, Table 4.4] shows the energy intensity for uranium mining. Rotty reported energies for conventional ore and for Chatanooga Shale. Table A.1-1 shows the Rotty values for conventional ore with $0.208 \% \mathrm{U}_{3} \mathrm{O}_{8}$ content, and $95 \%$ recovery (product leaving the mill divided by amount mined). Table A.1-2 converts Rotty's values to GJ $(e+t)$.

Table A.1-1. Energy intensity for uranium mining, per tonne of natural uranium, reported in Rotty [1975], using Rotty's units.

\begin{tabular}{|l|c|c|c|c|}
\hline \multirow{2}{*}{ Phase } & \multirow{2}{*}{$\begin{array}{c}\text { Electrical } \\
\text { MWh(e) }\end{array}$} & \multirow{2}{*}{$\begin{array}{c}\text { Thermal } \\
\text { MMBTU }\end{array}$} & $\begin{array}{c}\text { Electrical } \\
\text { MWh(e) }\end{array}$ & $\begin{array}{c}\text { Thermal } \\
\text { MMBTU }\end{array}$ \\
\cline { 4 - 5 } & 1.59 & 113 & - & - \\
\hline Oponstruction & 12.1 & 257 & 5.64 & 159 \\
\hline Total & $\mathbf{1 3 . 7}$ & $\mathbf{3 7 0}$ & $\mathbf{5 . 6 4}$ & $\mathbf{1 5 9}$ \\
\hline
\end{tabular}

Table A.1-2. Energy intensity for uranium mining, per tonne of natural uranium, reported in Rotty [1975], converted to $\mathrm{GJ}(\mathrm{e}+\mathrm{t})$.

\begin{tabular}{|r|c|c|c|c|c|}
\hline \multirow{2}{*}{ Phase } & \multirow{2}{*}{$\begin{array}{c}\text { Electrical } \\
\text { GJe }\end{array}$} & \multirow{2}{*}{$\begin{array}{c}\text { Thermal } \\
\text { GJt }\end{array}$} & $\begin{array}{c}\text { Embodied Material } \\
\text { MWh(e) }\end{array}$ & $\begin{array}{c}\text { Electrical } \\
\text { MWh(e) }\end{array}$ & $\begin{array}{c}\text { Total } \\
\text { GJ }\end{array}$ \\
\hline Construction & 5.7 & 119.2 & - & - & $\mathbf{1 2 4 . 9}$ \\
\hline Operation & 43.7 & 271.1 & 20.3 & 167.7 & $\mathbf{5 0 2 . 9}$ \\
\hline Total & $\mathbf{4 9 . 4}$ & $\mathbf{3 9 0 . 4}$ & $\mathbf{2 0 . 3}$ & $\mathbf{1 6 7 . 7}$ & $\mathbf{6 2 7 . 8}$ \\
\hline
\end{tabular}

Table A.1-3 scales the Rotty [1975] energies to the ore grade $(0.3 \%)$ and recovery fraction (95\%) used in this study. Table A.1-3 also includes a row for Decommissioning and Demolition (D\&D) energies, which are assumed to be $20 \%$ of the Construction energies.

The values in the EROI spreadsheet are based on 1.0 MTU of enriched uranium of LWR fuel. The U-235 enrichments used in this report are $0.25 \%$ depleted uranium $\left(\mathrm{e}_{\mathrm{d}}\right), 0.71 \%$ natural uranium $\left(\mathrm{e}_{\mathrm{n}}\right)$, and $5.0 \%$ fuel $\left(\mathrm{e}_{\mathrm{f}}\right)$. The masses are related as follows:

$$
\begin{aligned}
& \mathrm{m}_{\mathrm{d}}=\mathrm{m}_{\mathrm{f}} *\left(\mathrm{e}_{\mathrm{n}}-\mathrm{e}_{\mathrm{f}}\right) /\left(\mathrm{e}_{\mathrm{d}}-\mathrm{e}_{\mathrm{n}}\right) \\
& \mathrm{m}_{\mathrm{n}}=\mathrm{m}_{\mathrm{d}}+\mathrm{m}_{\mathrm{f}}
\end{aligned}
$$

Using the stated enrichment values, the depleted uranium mass in Table A.1-3 is 9.33 tonnes per tonne of enriched uranium in the fuel, and the output of the mining and milling operation is 10.33 tonnes per tonne of enriched uranium in the fuel. Table A.1-4 converts the values per tonne leaving the mill into values per tonne of enriched uranium fuel. Table A.1-4 is identical to Table 4.1-2 in the main body of this report. All the energies in Table A.1-4 are Final Energies. To obtain Primary energy intensities, Final Electrical energy intensities are multiplied by the thermal/electrical ratio (3.03 MWh-th/MWh-e for this study), and 
Final Thermal energy intensities are multiplied by the processing ratio (1.1 GJ-primary/GJ-final for this study).

Table A.1-3. Energy intensity for uranium mining [scaled from Rotty 1975], GJ(e+t)/tonne of natural uranium with $0.3 \%$ ore grade and $95 \%$ recovery.

\begin{tabular}{|c|c|c|c|c|c|}
\hline \multirow[b]{2}{*}{ Phase } & \multirow[b]{2}{*}{$\begin{array}{c}\text { Electrical } \\
\text { GJe }\end{array}$} & \multirow[b]{2}{*}{$\begin{array}{c}\text { Thermal } \\
\text { GJt }\end{array}$} & \multicolumn{2}{|c|}{ Embodied Material } & \multirow[b]{2}{*}{$\begin{array}{c}\text { Total } \\
\text { GJ }\end{array}$} \\
\hline & & & $\begin{array}{c}\text { Electrical } \\
\text { GJe }\end{array}$ & $\begin{array}{c}\text { Thermal } \\
\text { GJt }\end{array}$ & \\
\hline Construction & 4.0 & 82.7 & - & - & 86.6 \\
\hline Operation & 30.3 & 188.0 & 14.1 & 116.3 & 348.7 \\
\hline D\&D & 0.8 & 16.5 & - & - & 17.3 \\
\hline Total & 35.1 & 287.2 & 14.1 & 116.3 & 453 \\
\hline
\end{tabular}

Table A.1-4. Energy intensity for uranium mining [scaled from Rotty 1975], GJ(e+t)/MTU of enriched uranium fuel.

\begin{tabular}{|c|c|c|c|c|c|}
\hline \multirow[b]{2}{*}{ Phase } & \multirow[b]{2}{*}{$\begin{array}{c}\text { Electrical } \\
\text { GJe }\end{array}$} & \multirow[b]{2}{*}{$\begin{array}{c}\text { Thermal } \\
\text { GJt }\end{array}$} & \multicolumn{2}{|c|}{ Embodied Material } & \multirow[b]{2}{*}{$\begin{array}{c}\text { Total } \\
\text { GJ }\end{array}$} \\
\hline & & & $\begin{array}{c}\text { Electrical } \\
\text { GJe }\end{array}$ & $\begin{array}{c}\text { Thermal } \\
\text { GJt }\end{array}$ & \\
\hline Construction & 41.0 & 853 & - & - & 894 \\
\hline Operation & 313 & 1,941 & 145 & 1,201 & 3,600 \\
\hline D\&D & 8.2 & 171 & - & - & 179 \\
\hline Total & 362 & 2,965 & 145 & 1,201 & 4,674 \\
\hline
\end{tabular}




\section{A.2 Milling}

Rotty [1975, Table 4.9] shows the energy intensity for uranium milling. Rotty reported energies for conventional ore and for Chatanooga Shale. Table A.2-1 shows the Rotty values for conventional ore with $0.208 \% \mathrm{U}_{3} \mathrm{O}_{8}$ content, and $95 \%$ recovery (product leaving the mill divided by amount mined). Table A.2-2 converts Rotty's values to $\mathrm{GJ}(\mathrm{e}+\mathrm{t})$.

Table A.2-3 scales the Rotty [1975] energies to the ore grade $(0.3 \%)$ and recovery fraction $(95 \%)$ used in this study. Table A.2-3 also includes a row for Decommissioning and Demolition (D\&D) energies, which are assumed to be $20 \%$ of the Construction energies.

Table A.2-1. Energy intensity for uranium milling, per tonne of natural uranium, reported in Rotty [1975], using Rotty's units.

\begin{tabular}{|c|c|c|c|c|}
\hline \multirow[b]{2}{*}{ Phase } & \multirow[b]{2}{*}{$\begin{array}{c}\text { Electrical } \\
\text { GJe }\end{array}$} & \multirow[b]{2}{*}{$\begin{array}{c}\text { Thermal } \\
\text { GJt }\end{array}$} & \multicolumn{2}{|c|}{ Embodied Material } \\
\hline & & & $\begin{array}{c}\text { Electrical } \\
\text { GJe }\end{array}$ & $\begin{array}{c}\text { Thermal } \\
\text { GJt }\end{array}$ \\
\hline Construction & 0.71 & 31 & - & - \\
\hline Operation & 17.25 & 335 & 4.13 & 159 \\
\hline Total & 18.0 & 366 & 4.13 & 159 \\
\hline
\end{tabular}

Table A.2-2. Energy intensity for uranium milling, per tonne of natural uranium, reported in Rotty [1975], converted to $\mathrm{GJ}(\mathrm{e}+\mathrm{t})$.

\begin{tabular}{|l|c|c|c|c|c|}
\hline \multirow{2}{*}{ Phase } & \multirow{2}{*}{$\begin{array}{c}\text { Electrical } \\
\text { GJe }\end{array}$} & $\begin{array}{c}\text { Thermal } \\
\text { GJt }\end{array}$ & $\begin{array}{c}\text { Electrical } \\
\text { GJe }\end{array}$ & $\begin{array}{c}\text { Thermal } \\
\text { GJt }\end{array}$ & \multirow{2}{*}{$\begin{array}{c}\text { Total } \\
\text { GJ }\end{array}$} \\
\cline { 4 - 5 } Construction & 2.56 & 32.7 & - & - & $\mathbf{3 5 . 3}$ \\
\hline Operation & 62.1 & 353 & 14.9 & 168 & $\mathbf{5 9 8}$ \\
\hline Total & $\mathbf{6 4 . 7}$ & $\mathbf{3 8 6}$ & $\mathbf{1 4 . 9}$ & $\mathbf{1 6 8}$ & $\mathbf{6 3 3}$ \\
\hline
\end{tabular}

The values in the EROI spreadsheet are based on 1.0 MTU of enriched uranium of LWR fuel. The values per tonne leaving the mill are converted into values per tonne of enriched uranium fuel in Table A.2-4, as was done for mining in Appendix A.1. Table A.2-4 is identical to Table 4.2-1 in the main body of this report. All the energies in Table A.2-4 are Final Energies.

It should be noted that identical values of thermal energies of embodied material in mining and milling (159 in each case) is not a typographical error in this appendix or in Rotty's Summary Tables (4.4 and 4.9). Rotty's Detailed Tables (4.2 and 4.7) show 159.22 for mining, and 158.77 for milling, indicating that the Summary Tables are correct. 
Table A.2-3. Energy intensity for uranium milling [scaled from Rotty 1975], GJ(e+t)/tonne of natural uranium with $0.3 \%$ ore grade and $95 \%$ recovery.

\begin{tabular}{|c|c|c|c|c|c|}
\hline \multirow[b]{2}{*}{ Phase } & \multirow[b]{2}{*}{$\begin{array}{c}\text { Electrical } \\
\text { GJe }\end{array}$} & \multirow[b]{2}{*}{$\begin{array}{c}\text { Thermal } \\
\text { GJt }\end{array}$} & \multicolumn{2}{|c|}{ Embodied Material } & \multirow[b]{2}{*}{$\begin{array}{c}\text { Total } \\
\text { GJ }\end{array}$} \\
\hline & & & $\begin{array}{c}\text { Electrical } \\
\text { GJe }\end{array}$ & $\begin{array}{c}\text { Thermal } \\
\text { GJt }\end{array}$ & \\
\hline Construction & 1.77 & 22.7 & - & - & 24.4 \\
\hline Operation & 43.1 & 245 & 10.3 & 116 & 415 \\
\hline D\&D & 0.354 & 4.54 & - & - & 4.89 \\
\hline Total & 45.2 & 272 & 10.3 & 116 & 444 \\
\hline
\end{tabular}

Table A.2-4 Energy intensity for uranium milling, GJ $(\mathrm{e}+\mathrm{t}) / \mathrm{MTU}$ of enriched uranium fuel.

\begin{tabular}{|c|c|c|c|c|c|}
\hline \multirow[b]{2}{*}{ Phase } & \multirow[b]{2}{*}{$\begin{array}{c}\text { Electrical } \\
\text { GJe }\end{array}$} & \multirow[b]{2}{*}{$\begin{array}{c}\text { Thermal } \\
\text { GJt }\end{array}$} & \multicolumn{2}{|c|}{ Embodied Material } & \multirow[b]{2}{*}{$\begin{array}{c}\text { Total } \\
\text { GJ }\end{array}$} \\
\hline & & & $\begin{array}{c}\text { Electrical } \\
\text { GJe }\end{array}$ & $\begin{array}{c}\text { Thermal } \\
\text { GJt }\end{array}$ & \\
\hline Construction & 18.3 & 234 & - & - & 252 \\
\hline Operation & 445 & 2,530 & 106 & 1,201 & 4,282 \\
\hline D\&D & 3.66 & 46.8 & - & - & 50.5 \\
\hline Total & 467 & 2,811 & 106 & 1,201 & 4,585 \\
\hline
\end{tabular}




\section{A.3 Conversion}

Rotty [1975, Table 5.1] shows the energy intensity for uranium conversion. Table A.3-1 shows the Rotty annual values for a 6180 metric ton of natural uranium per year plant.

Table A.3-1. Energy intensity for uranium conversion, per year, for a dry conversion plant processing 6180 metric tons of natural uranium annually, reported in Rotty [1975], using Rotty's units.

\begin{tabular}{|c|c|c|c|c|c|c|}
\hline \multirow[b]{2}{*}{ Phase } & \multirow[b]{2}{*}{$\begin{array}{c}\text { Electrical } \\
\text { MWh(e) }\end{array}$} & \multirow[b]{2}{*}{$\begin{array}{c}\text { Thermal } \\
\text { MMBTU }\end{array}$} & \multicolumn{2}{|c|}{ Embodied Material } & \multicolumn{2}{|c|}{ Total } \\
\hline & & & $\begin{array}{c}\text { Electrical } \\
\operatorname{MWh}(\mathrm{e})\end{array}$ & $\begin{array}{l}\text { Thermal } \\
\text { MMBTU }\end{array}$ & $\begin{array}{c}\text { Electrical } \\
\text { MWh(e) }\end{array}$ & $\begin{array}{l}\text { Thermal } \\
\text { MMBTU }\end{array}$ \\
\hline Construction & 39 & 8,473 & 951 & 37,400 & 991 & 45,873 \\
\hline Operation & 63,000 & $7,629,400$ & 26,281 & 673,423 & 89,281 & $8,302,823$ \\
\hline Total & 63,039 & $7,637,873$ & 27,232 & 710,823 & 90,272 & $8,348,696$ \\
\hline
\end{tabular}

Dividing the electrical total (90,272 MWh(e) per year for the 6180 tonne/yr) plant by 6180 results in Rotty's value of $14.6 \mathrm{MWh}(\mathrm{e})$ per metric ton natural uranium processed. Similarly, the thermal total of $8,348,696 \mathrm{MMBTU} / \mathrm{yr}$ for the plant results in Rotty's value of 1,351 MMBTU per metric ton natural uranium processed. Table A.3-2 converts Rotty's individual table values to energy per metric ton of natural uranium converted to $\mathrm{UF}_{6}$, with the energy unit being GJ.

Table A.3-2. Energy intensity for uranium conversion, per tonne of natural uranium processed.

\begin{tabular}{|r|c|c|c|c|c|}
\hline \multirow{2}{*}{ Phase } & \multirow{2}{*}{$\begin{array}{c}\text { Electrical } \\
\text { GJe }\end{array}$} & \multirow{2}{*}{$\begin{array}{c}\text { Thermal } \\
\text { GJt }\end{array}$} & $\begin{array}{c}\text { Electrical } \\
\text { GJe }\end{array}$ & $\begin{array}{c}\text { Thermal } \\
\text { GJt }\end{array}$ & \multirow{2}{*}{$\begin{array}{c}\text { Total } \\
\text { GJ }\end{array}$} \\
\cline { 5 - 6 } Construction & 0.0230 & 1.45 & 0.554 & 6.38 & $\mathbf{8 . 4 1}$ \\
\hline Operation & 36.7 & 1,302 & 15.3 & 115 & $\mathbf{1 4 6 9}$ \\
\hline Total & $\mathbf{3 6 . 7}$ & $\mathbf{1 , 3 0 4}$ & $\mathbf{1 5 . 9}$ & $\mathbf{1 2 1}$ & $\mathbf{1 4 7 8}$ \\
\hline
\end{tabular}

DOE [2012] provides similar information for operation of a wet conversion facility, using data from their reference AEC, 1974, as shown in Table A.3-3.

Table A.3-3. Energy intensity for uranium conversion, per tonne of natural uranium processed, from DOE [2012, Tables 5-13 and 5-14], using wet conversion.

\begin{tabular}{|c|c|c|c|c|c|c|}
\hline \multirow[b]{2}{*}{ Phase } & \multirow[b]{2}{*}{$\begin{array}{c}\text { Electrical } \\
\text { GJe }\end{array}$} & \multirow[b]{2}{*}{$\begin{array}{c}\text { Thermal } \\
\text { GJt }\end{array}$} & \multicolumn{3}{|c|}{ Embodied Material } & \multirow[b]{2}{*}{$\begin{array}{c}\text { Total } \\
\text { GJ }\end{array}$} \\
\hline & & & $\begin{array}{c}\text { Electrical } \\
\text { GJe }\end{array}$ & $\begin{array}{c}\text { Thermal } \\
\text { GJt }\end{array}$ & $\begin{array}{c}\text { Inputs } \\
\text { GJt }\end{array}$ & \\
\hline Operation & 39.6 & 134 & 32.4 & 62.4 & 1.24 & 269 \\
\hline
\end{tabular}

Because the thermal energy for dry conversion is nearly an order of magnitude higher than for wet conversion, this study uses the DOE [2012] wet conversion values for operation. Combining the 
appropriate rows of Tables A.3-2 and A.3-3, and adding a D\&D row that is $20 \%$ of construction, results in Table A.3-4.

The EROI spreadsheet values are based on 1.0 MTU of enriched uranium of LWR fuel. Table A.3-5 converts the values per tonne of natural uranium into values per tonne of enriched uranium fuel, as was done for mining in Appendix A.1. Table A.3-5 is identical to Table 4.3-1 in the main body of this report. All the energies in Table A.3-5 are Final Energies. The transportation energy is from Appendix A.7.

Table A.3-4. Energy intensity for uranium conversion, per MT of natural uranium processed, this study.

\begin{tabular}{|c|c|c|c|c|c|c|c|}
\hline \multirow[b]{2}{*}{ Phase } & \multirow[b]{2}{*}{$\begin{array}{c}\text { Electrical } \\
\text { GJe }\end{array}$} & \multirow[b]{2}{*}{$\begin{array}{c}\text { Thermal } \\
\text { GJt }\end{array}$} & \multicolumn{3}{|c|}{ Embodied Material } & \multirow[b]{2}{*}{ Transportation } & \multirow[b]{2}{*}{$\begin{array}{c}\text { Total } \\
\text { GJ }\end{array}$} \\
\hline & & & $\begin{array}{c}\text { Electrical } \\
\text { GJe }\end{array}$ & $\begin{array}{c}\text { Thermal } \\
\text { GJt }\end{array}$ & $\begin{array}{c}\text { Inputs } \\
\text { GJt }\end{array}$ & & \\
\hline Construction & 0.0230 & 1.45 & 0.554 & 6.38 & - & - & 8.41 \\
\hline Operation & 39.6 & 134 & 32.4 & 62.4 & 1.24 & 1.05 & 271 \\
\hline $\mathrm{D} \& \mathrm{D}$ & 0.00459 & 0.289 & - & - & - & - & 0.294 \\
\hline Total & 39.6 & 136 & 32.9 & 68.8 & 1.24 & 1.05 & 279 \\
\hline
\end{tabular}

Table A.3-5. Energy intensity for uranium conversion, per MT of enriched uranium fuel, this study.

\begin{tabular}{|c|c|c|c|c|c|c|c|}
\hline \multirow[b]{2}{*}{ Phase } & \multirow[b]{2}{*}{$\begin{array}{c}\text { Electrical } \\
\text { GJe }\end{array}$} & \multirow[b]{2}{*}{$\begin{array}{c}\text { Thermal } \\
\text { GJt }\end{array}$} & \multicolumn{3}{|c|}{ Embodied Material } & \multirow[b]{2}{*}{ Transportation } & \multirow[b]{2}{*}{$\begin{array}{c}\text { Total } \\
\text { GJ }\end{array}$} \\
\hline & & & $\begin{array}{c}\text { Electrical } \\
\text { GJe }\end{array}$ & $\begin{array}{c}\text { Thermal } \\
\text { GJt }\end{array}$ & $\begin{array}{c}\text { Inputs } \\
\text { GJt }\end{array}$ & & \\
\hline Construction & 0.237 & 14.9 & 5.72 & 65.9 & - & - & 86.8 \\
\hline Operation & 409 & 1,383 & 334 & 644 & 12.8 & 10.8 & 2,794 \\
\hline D\&D & 0.0474 & 2.99 & - & - & - & - & 3.03 \\
\hline Total & 409 & 1,401 & 340 & 710 & 12.8 & 10.8 & 2,884 \\
\hline
\end{tabular}




\section{A.4 Enrichment}

Rotty [1975, Table 6.3] shows the energy inputs for uranium enrichment in a plant with annual capacity of $8.75 \times 10^{6} \mathrm{~kg}-\mathrm{SWU}$, and a plant life of $30 \mathrm{yr}$ (Rotty divided the overall construction energies by the total SWU produced in the plant lifetime (i.e., capacity times lifetime). Rotty's values are shown in Table A.4-1.

Table A.4-1. Energy intensity for uranium enrichment, per SWU of capacity, for a gaseous diffusion plant with 8.75 million kg-SWU capacity and lifetime of $30 \mathrm{yr}$, from Rotty [1975].

\begin{tabular}{|l|c|c|c|c|}
\hline \multirow{2}{*}{ Phase } & \multirow{2}{*}{$\begin{array}{c}\text { Electrical } \\
\text { MWh(e) }\end{array}$} & \multirow{2}{*}{$\begin{array}{c}\text { Thermal } \\
\text { MMBTU }\end{array}$} & $\begin{array}{c}\text { Electrical } \\
\text { MWh(e) }\end{array}$ & $\begin{array}{c}\text { Thermal } \\
\text { MMBTU }\end{array}$ \\
\cline { 4 - 5 } Construction & 0.000328 & 0.0704 & 0.0074 & 0.255 \\
\hline Operation & 2.81 & 0.336 & 0.00580 & 0.137 \\
\hline Total & $\mathbf{2 . 8 1}$ & $\mathbf{0 . 4 0 6}$ & $\mathbf{0 . 0 1 3 2}$ & $\mathbf{0 . 3 9 2}$ \\
\hline
\end{tabular}

The Rotty [1975] values are converted to GJ $(e+t)$ in Table A.4-2. A row is added for D\&D, at $20 \%$ of the construction energy. Because modern enrichment plants use gas centrifuges with direct electrical energy requirements ranging from $0.18-1.02 \mathrm{GJ}(\mathrm{e}+\mathrm{t})$ per $\mathrm{kg}-\mathrm{SWU}$, this study assumes a mixture of primarily gas centrifuge with some gaseous diffusion contribution, with a value of 0.36 GJe per kg-SWU. Table A.4-3 repeats Rotty's values, but with this study's operational electrical energy value rather than Rotty's.

Table A.4-2. Rotty's values, converted to GJ. Enrichment energy per SWU of capacity.

\begin{tabular}{|c|c|c|c|c|c|}
\hline \multirow[b]{2}{*}{ Phase } & \multirow[b]{2}{*}{$\begin{array}{c}\text { Electrical } \\
\text { GJe }\end{array}$} & \multirow[b]{2}{*}{$\begin{array}{c}\text { Thermal } \\
\text { GJt }\end{array}$} & \multicolumn{2}{|c|}{ Embodied Material } & \multirow[b]{2}{*}{$\begin{array}{c}\text { Total } \\
\text { GJ }\end{array}$} \\
\hline & & & $\begin{array}{c}\text { Electrical } \\
\text { GJe }\end{array}$ & $\begin{array}{c}\text { Thermal } \\
\text { GJt }\end{array}$ & \\
\hline Construction & 0.00118 & 0.0742 & 0.0266 & 0.269 & 0.371 \\
\hline Operation & 10.12 & 0.354 & 0.0209 & 0.145 & 10.6 \\
\hline D\&D & 0.000236 & 0.0148 & - & - & 0.0151 \\
\hline Total & 10.1 & 0.443 & 0.0475 & 0.414 & 11.0 \\
\hline
\end{tabular}

The amount of separative work required depends on the enrichments and relative amounts of the incoming natural uranium, the product enriched uranium fuel, and the depleted uranium waste. The relative amounts of natural uranium, enriched fuel, and waste depleted uranium are calculated in Appendix A.1, and are, respectively, 10.33 MTU, 1.0 MTU, and 9.33 MTU for the representative enrichments of $0.71 \%$ natural uranium, $5.0 \%$ enriched uranium fuel, and $0.25 \%$ depleted uranium waste used in this study. The separative work is calculated from value functions for each stream, where the value function is

$$
(2 \mathrm{e}-1) \ln [\mathrm{e} /(1-\mathrm{e})]
$$


and e is the enrichment of that stream. For the representative values of enrichment used in this study, the value functions are 4.87, 2.65, and 5.96 for the natural uranium, enriched fuel, and depleted uranium, respectively. The separative work is

$$
1000 \mathrm{~kg}\left\{\mathrm{~V}_{\mathrm{f}}-\left(\mathrm{m}_{\mathrm{n}} / \mathrm{m}_{\mathrm{f}}\right) \mathrm{V}_{\mathrm{n}}+\left[\left(\mathrm{m}_{\mathrm{n}} / \mathrm{m}_{\mathrm{f}}\right)-1\right] \mathrm{V}_{\mathrm{d}}\right\}
$$

where $V_{f}, V_{n}$, and $V_{d}$ are the value functions of the enriched fuel, natural uranium, and depleted uranium, respectively, and $m_{n}$ and $m_{f}$ are the relative masses of natural uranium and enriched fuel, respectively. For the representative enrichments used in this study, the separative work for 1 MTU of enriched fuel is $7932 \mathrm{~kg}-\mathrm{SWU}$. Multiplying the energies in Table A.4-3 by this value results in Table A.4-4, which is identical to Table 4.4-2 in the main body of this report. All the energies in Table A.4-4 are Final Energies. The transportation energy is from Appendix A.7.

Table A.4-3. Rotty's values, except for substitution of gas centrifuge dominated direct electrical energy during operation. Enrichment energy per SWU.

\begin{tabular}{|c|c|c|c|c|c|}
\hline \multirow[b]{2}{*}{ Phase } & \multirow[b]{2}{*}{$\begin{array}{c}\text { Electrical } \\
\text { GJe }\end{array}$} & \multirow[b]{2}{*}{$\begin{array}{c}\text { Thermal } \\
\text { GJt }\end{array}$} & \multicolumn{2}{|c|}{ Embodied Material } & \multirow[b]{2}{*}{$\begin{array}{c}\text { Total } \\
\text { GJ }\end{array}$} \\
\hline & & & $\begin{array}{c}\text { Electrical } \\
\text { GJe }\end{array}$ & $\begin{array}{c}\text { Thermal } \\
\text { GJt }\end{array}$ & \\
\hline Construction & 0.0011 & 0.0742 & 0.0266 & 0.269 & 0.371 \\
\hline Operation & 0.36 & 0.35 & 0.0209 & 0.145 & 0.880 \\
\hline $\mathrm{D} \& \mathrm{D}$ & 0.00024 & 0.0148 & - & - & 0.0151 \\
\hline Total & 0.361 & 0.443 & 0.0475 & 0.414 & 1.27 \\
\hline
\end{tabular}

Table A.4-4. Enrichment energy for 1 MTU of enriched uranium fuel, this study.

\begin{tabular}{|l|c|c|c|c|c|c|}
\hline \multirow{2}{*}{ Phase } & \multirow{2}{*}{$\begin{array}{c}\text { Electrical } \\
\text { GJe }\end{array}$} & \multirow{2}{*}{$\begin{array}{c}\text { Thermal } \\
\text { GJt }\end{array}$} & $\begin{array}{c}\text { Electrical } \\
\text { GJe }\end{array}$ & $\begin{array}{c}\text { Thermal } \\
\text { GJt }\end{array}$ & Transportation & $\begin{array}{c}\text { Total } \\
\text { GJ }\end{array}$ \\
\hline Construction & 9.35 & 589 & 211 & 2,135 & & $\mathbf{2 , 9 4 5}$ \\
\hline Operation & 2,856 & 2,808 & 166 & 1,148 & 23.4 & $\mathbf{7 , 0 0 1}$ \\
\hline D\&D & 1.87 & 118 & - & - & & $\mathbf{1 2 0}$ \\
\hline Total & $\mathbf{2 , 8 6 7}$ & $\mathbf{3 , 5 1 4}$ & $\mathbf{3 7 7}$ & $\mathbf{3 , 2 8 3}$ & $\mathbf{2 3 . 4}$ & $\mathbf{1 0 , 0 6 5}$ \\
\hline
\end{tabular}




\section{A.5 Deconversion}

Because Rotty [1975] has no reported energy intensity values for construction or D\&D of a deconversion plant, the construction and D\&D energy intensities are assumed to be equivalent to those shown in Table A.3-4 for the conversion plant. Table A.5-1 shows those values, which are per tonne of depleted uranium processed into $\mathrm{DU}_{3} \mathrm{O}_{8}$. The enriched fuel goes to the fuel fabrication plant where it is processed into enriched $\mathrm{UO}_{2}$ (see Appendix A.6). Table A.5-1 also shows energy intensities for operation of the deconversion plant, taken from DOE [2012, Table 6-115]. The embodied material energy value of negative $54.2 \mathrm{GJ}(\mathrm{e}+\mathrm{t}) / \mathrm{MTU}$ of DU is the total of 14.3 units of energy to produce $\mathrm{CaO}, \mathrm{NH}_{3}, \mathrm{KOH}, \mathrm{H}_{2}$, and $\mathrm{N}_{2}$; and a credit of 68.5 units of energy for the HF that can be reused in the conversion process.

The EROI spreadsheet values are based on 1.0 MTU of enriched uranium of LWR fuel. Table A.5-2 converts the values per tonne of depleted uranium into values per tonne of enriched uranium fuel, by multiplying by 9.33 MTU of DU per MTU of enriched fuel. Table A.5-2 is identical to Table 4.5-1 in the main body of this report. All the energies in Table A.5-2 are Final Energies.

Table A.5-1. Energy intensity for uranium deconversion, per MT depleted uranium processed, this study.

\begin{tabular}{|c|c|c|c|c|c|}
\hline \multirow[b]{2}{*}{ Phase } & \multirow[b]{2}{*}{$\begin{array}{c}\text { Electrical } \\
\text { GJe }\end{array}$} & \multirow[b]{2}{*}{$\begin{array}{c}\text { Thermal } \\
\text { GJt }\end{array}$} & \multicolumn{2}{|c|}{ Embodied Material } & \multirow[b]{2}{*}{$\begin{array}{c}\text { Total } \\
\text { GJ }\end{array}$} \\
\hline & & & $\begin{array}{c}\text { Electrical } \\
\text { GJe }\end{array}$ & $\begin{array}{c}\text { Thermal } \\
\text { GJt }\end{array}$ & \\
\hline Construction & 0.023 & 1.45 & 0.55 & 6.4 & 8.41 \\
\hline Operation & 11.6 & 4.17 & -21.9 & -32.3 & -38.4 \\
\hline $\mathrm{D} \& \mathrm{D}$ & 0.00459 & 0.289 & - & - & 0.294 \\
\hline Total & 11.7 & 5.91 & -21.4 & -25.9 & -29.7 \\
\hline
\end{tabular}

Table A.5-2. Energy intensity for uranium deconversion, per MT enriched uranium fuel, this study.

\begin{tabular}{|c|c|c|c|c|c|}
\hline \multirow[b]{2}{*}{ Phase } & \multirow[b]{2}{*}{$\begin{array}{c}\text { Electrical } \\
\text { GJe }\end{array}$} & \multirow[b]{2}{*}{$\begin{array}{c}\text { Thermal } \\
\text { GJt }\end{array}$} & \multicolumn{2}{|c|}{ Embodied Material } & \multirow[b]{2}{*}{$\begin{array}{c}\text { Total } \\
\text { GJ }\end{array}$} \\
\hline & & & $\begin{array}{c}\text { Electrical } \\
\text { GJe }\end{array}$ & $\begin{array}{c}\text { Thermal } \\
\text { GJt }\end{array}$ & \\
\hline Construction & 0.214 & 13.5 & 5.17 & 59.5 & 78.4 \\
\hline Operation & 108 & 38.9 & -204 & -301 & -358 \\
\hline D\&D & 0.0428 & 2.70 & - & - & 2.74 \\
\hline Total & 109 & 55.1 & -199 & -242 & -277.2 \\
\hline
\end{tabular}




\section{A.6 Fuel Fabrication}

Rotty [1975, Table 7.1] shows the energy intensity for fuel fabrication without plutonium recycle, for a plant with capacity of 600 MTU of fuel per year. Table A.6-1 shows the Rotty annual values. The values are converted to GJ per MTU of enriched fuel in Table A.6-2. The D\&D costs are assumed to be $20 \%$ of the construction costs. Table A.6-2 is identical to Table 4.6-1 in the main body of this report. All the energies in Table A.6-2 are Final Energies. The transportation energy is from Appendix A.7

Table A.6-1. Energy intensity for fuel fabrication, per year, for a plant processing 600 MT of enriched uranium fuel annually, reported in Rotty [1975], using Rotty's units.

\begin{tabular}{|r|c|c|c|c|c|c|}
\hline \multirow{2}{*}{ Phase } & \multirow{2}{*}{$\begin{array}{c}\text { Electrical } \\
\text { MWh(e) }\end{array}$} & \multirow{2}{*}{$\begin{array}{c}\text { Thermal } \\
\text { MMBTU }\end{array}$} & $\begin{array}{c}\text { Electrical } \\
\text { MWh(e) }\end{array}$ & $\begin{array}{c}\text { Thermal } \\
\text { MMBTU }\end{array}$ & $\begin{array}{c}\text { Electrical } \\
\text { MWh(e) }\end{array}$ & $\begin{array}{c}\text { Thermal } \\
\text { MMBTU }\end{array}$ \\
\cline { 4 - 7 } & & 5,411 & 533 & 17,748 & $\mathbf{5 5 8}$ & $\mathbf{2 3 , 1 5 9}$ \\
\hline Openstruction & 25.2 & 129,906 & 120,489 & $1,386,280$ & $\mathbf{1 7 9 , 9 8 9}$ & $\mathbf{1 , 5 1 6 , 1 8 6}$ \\
\hline Total & $\mathbf{5 9 , 5 2 5}$ & $\mathbf{1 3 5 , 3 1 7}$ & $\mathbf{1 2 1 , 0 2 2}$ & $\mathbf{1 , 4 0 4 , 0 2 8}$ & $\mathbf{1 8 0 , 5 4 7}$ & $\mathbf{1 , 5 3 9 , 3 4 5}$ \\
\hline
\end{tabular}

Table A.6-2. Energy intensity for fuel fabrication, in GJ/MTU of enriched uranium fuel.

\begin{tabular}{|c|c|c|c|c|c|c|}
\hline \multirow[b]{2}{*}{ Phase } & \multirow[b]{2}{*}{$\begin{array}{c}\text { Electrical } \\
\text { GJe }\end{array}$} & \multirow[b]{2}{*}{$\begin{array}{c}\text { Thermal } \\
\text { GJt }\end{array}$} & \multicolumn{2}{|c|}{ Embodied Material } & \multirow[b]{2}{*}{$\begin{array}{c}\text { Transportation } \\
\text { GJt }\end{array}$} & \multirow[b]{2}{*}{$\begin{array}{c}\text { Total } \\
\text { GJ }\end{array}$} \\
\hline & & & $\begin{array}{c}\text { Electrical } \\
\text { GJe }\end{array}$ & $\begin{array}{c}\text { Thermal } \\
\text { GJt }\end{array}$ & & \\
\hline Construction & 0.151 & 9.51 & 3.20 & 31.2 & - & 44.1 \\
\hline Operation & 357 & 228 & 723 & 2,438 & 0.9 & 3,746 \\
\hline $\mathrm{D} \& \mathrm{D}$ & 0.0302 & 1.90 & - & - & - & 1.93 \\
\hline Total & 357 & 240 & 726 & 2,469 & 0.9 & 3,792 \\
\hline
\end{tabular}




\section{A.7 Front-End Transportation}

Schneider [2010, Table 8.6] shows the energy intensity for truck and rail transportation. Table A.7-1 shows the Schneider values, and Table A.7-2 converts them to one MTU of enriched fuel basis. Table A.7-2 also shows this study's assumed representative transportation distances. This study does not consider the energy used in manufacturing or disposing of the transport vehicles, and thus all energy impacts are considered in the Operation Phase. Table A.7-2 is identical to Table 4.7-1 in the main body of this report. All the energies in Table A.7-2 are Final Energies.

Table A.7-1. Energy intensity for transportation, from Schneider [2010].

\begin{tabular}{|c|c|c|c|}
\hline Route & Mass Basis & $\begin{array}{c}\text { Truck } \\
\text { GJt/km/MTU }\end{array}$ & $\begin{array}{c}\text { Rail } \\
\text { GJt } / \mathbf{k m} / \mathbf{M T U}\end{array}$ \\
\hline Mill to Conversion & $\mathrm{NU}$ in $\mathrm{U}_{3} \mathrm{O}_{8}$ & 0.00105 & - \\
\hline Conversion to Enrichment & $\mathrm{NU}$ in $\mathrm{UF}_{6}$ & 0.00261 & 0.00151 \\
\hline Enrichment to Fabrication & Enriched $\mathrm{UF}_{6}$ & 0.00545 & 0.00316 \\
\hline Fabrication to PWR & Enriched $\mathrm{U}$ in $\mathrm{UO}_{2}$ Assemblies & 0.0193 & - \\
\hline Fabrication to BWR & Enriched $\mathrm{U}$ in $\mathrm{UO}_{2}$ Assemblies & 0.00809 & - \\
\hline
\end{tabular}

Table A.7-2. Energy intensity for transportation, for this study's representative fuel cycle parameters.

\begin{tabular}{|l|c|c|c|}
\hline \multicolumn{1}{|c|}{ Route } & Mode & km & $\begin{array}{c}\text { Energy } \\
\text { GJt/MTU }\end{array}$ \\
\hline Mill to Conversion & Truck & 1000 & 10.8 \\
\hline Conversion to Enrichment & Rail & 1500 & 23.4 \\
\hline Enrichment to Fabrication & Rail & 300 & 0.9 \\
\hline Fabrication to PWR & Truck & 1500 & 29.0 \\
\hline Total & & & $\mathbf{6 4 . 1}$ \\
\hline
\end{tabular}




\section{A.8 Reactor}

To place the reactor output energy on a per unit of fuel basis, the reactor power of $1 \mathrm{GWe}$ is multiplied by the thermal/electrical inverse efficiency $(1 / 0.330)$, the capacity factor of $90 \%$, and the 50 year lifetime, to obtain $49,807 \mathrm{GWd}(\mathrm{th})$ of operation. Dividing this number by the burnup of $50 \mathrm{GWd}(\mathrm{th}) / \mathrm{MTU}$ produces a lifetime fuel requirement of 996.14 MTU. Table A.8-1 shows the output energy in various units, as well as the lifetime fuel requirements.

Table A.8-1. Energy output for a 1000 MWe PWR with 50 year lifetime, 90\% capacity factor, 33\% thermal efficiency, and $50 \mathrm{GWd}(\mathrm{th}) /$ MTU burnup.

\begin{tabular}{|c|c|c|c|}
\hline Phase & Inputs & $\begin{array}{l}\text { Thermal } \\
\text { (Primary) }\end{array}$ & $\begin{array}{c}\text { Electrical } \\
\text { (Final) }\end{array}$ \\
\hline Power, GW & $33 \%$ thermal efficiency & 3.0303 & 1.0 \\
\hline GWyr & $\begin{array}{c}90 \% \text { capacity factor } \\
50 \mathrm{yr} \text { lifetime }\end{array}$ & 136.4 & 45 \\
\hline GWd & $365.25 \mathrm{day} / \mathrm{yr}$ & 49,807 & 16,436 \\
\hline GJ & $24 * 60 * 60 \mathrm{sec} /$ day & $4,303,309,091$ & $1,420,092,000$ \\
\hline MTU lifetime & $50 \mathrm{GWd}(\mathrm{th}) / \mathrm{MTU}$ & \multicolumn{2}{|c|}{ 996.14 MTU enriched fuel } \\
\hline GJ/MTU & & $4,320,000$ & $1,425,600$ \\
\hline
\end{tabular}

Rotty [1975, Table 8.2] shows the energy intensity for constructing and operating a 1000 MW(e) nuclear reactor, assuming a plant life of 30 years. Table A.8-2 shows the Rotty annual values. Table A.8-3 adjusts Rotty's values for the longer reactor lifetime in this study, converts them to a lifetime total, and changes the units to GJ. Construction costs are assumed to be insensitive to plant lifetime, and hence the construction row is multiplied by Rotty's $30 \mathrm{yr}$ lifetime. Operating costs are assumed to be the same for each year of operation, and thus are multiplied by this study's 50 year lifetime. A D\&D row is added, with electrical and thermal values the same as for construction (due to the added energy cost of D\&D of a contaminated facility), and with no embodied material costs.

Table A.8-2. Annual energy intensity for constructing and operating a 1000 MWe PWR, reported in Rotty [1975], using Rotty's units.

\begin{tabular}{|r|c|c|c|c|c|c|}
\hline \multirow{2}{*}{ Phase } & \multirow{2}{*}{$\begin{array}{c}\text { Electrical } \\
\text { MWh(e) }\end{array}$} & \multirow{2}{*}{$\begin{array}{c}\text { Thermal } \\
\text { MMBTU }\end{array}$} & $\begin{array}{c}\text { Electrical } \\
\text { MWh(e) }\end{array}$ & $\begin{array}{c}\text { Thermal } \\
\text { MMBTU }\end{array}$ & $\begin{array}{c}\text { Electrical } \\
\text { MWh(e) }\end{array}$ & $\begin{array}{c}\text { Thermal } \\
\text { MMBTU }\end{array}$ \\
\cline { 4 - 7 } Construction & 288 & 61,933 & 6,543 & 257,467 & $\mathbf{6 , 8 3 2}$ & $\mathbf{3 1 9 , 4 0 0}$ \\
\hline Operation & - & 12,607 & 8,551 & 272,635 & $\mathbf{8 , 5 5 1}$ & $\mathbf{2 8 5 , 2 4 2}$ \\
\hline Total & $\mathbf{2 8 8}$ & $\mathbf{7 4 , 5 4 0}$ & $\mathbf{1 5 , 0 9 4}$ & $\mathbf{5 3 0 , 1 0 2}$ & $\mathbf{1 5 , 3 8 3}$ & $\mathbf{6 0 4 , 6 4 2}$ \\
\hline
\end{tabular}


Table A.8-3. Lifetime energy intensity for constructing, operating, and demolishing a 1000 MWe PWR.

\begin{tabular}{|c|c|c|c|c|c|}
\hline \multirow[b]{2}{*}{ Phase } & \multirow[b]{2}{*}{$\begin{array}{c}\text { Electrical } \\
\text { GJe }\end{array}$} & \multirow[b]{2}{*}{$\begin{array}{c}\text { Thermal } \\
\text { GJt }\end{array}$} & \multicolumn{2}{|c|}{ Embodied Material } & \multirow[b]{2}{*}{$\begin{array}{c}\text { Total } \\
\text { GJ }\end{array}$} \\
\hline & & & $\begin{array}{c}\text { Electrical } \\
\text { GJe }\end{array}$ & $\begin{array}{c}\text { Thermal } \\
\text { GJt }\end{array}$ & \\
\hline Construction & 31,140 & $1,960,190$ & 706,680 & $8,148,820$ & $10,846,830$ \\
\hline Operation & - & 665,019 & $1,539,180$ & $14,381,496$ & $16,585,696$ \\
\hline $\mathrm{D} \& \mathrm{D}$ & 31,140 & $1,960,190$ & - & - & $1,991,330$ \\
\hline Total & 62,280 & $4,585,399$ & $2,245,860$ & $22,530,316$ & $29,423,884$ \\
\hline
\end{tabular}

The lifetime requirement for enriched fuel derived in Table A.8-1 can be substituted into the energy intensities of Table A.8-3 to obtain energy intensities based on 1 MTU of enriched fuel, as shown in Table A.8-4. All the energies in Table A.8-4 are Final Energies. The transportation energy is from Appendix A.7. Table A.8-4 is identical to Table 5.2-1 in the main body of this report.

Table A.8-4. Energy intensity for constructing, operating, and demolishing a 1000 MWe PWR, per MTU of enriched uranium fuel.

\begin{tabular}{|c|c|c|c|c|c|c|}
\hline \multirow[b]{2}{*}{ Phase } & \multirow[b]{2}{*}{$\begin{array}{l}\text { Electrical } \\
\text { GJe }\end{array}$} & \multirow[b]{2}{*}{$\begin{array}{c}\text { Thermal } \\
\text { GJt }\end{array}$} & \multicolumn{2}{|c|}{ Embodied Material } & \multirow[b]{2}{*}{$\begin{array}{c}\text { Transportation } \\
\text { GJt }\end{array}$} & \multirow[b]{2}{*}{$\begin{array}{c}\text { Total } \\
\text { GJ }\end{array}$} \\
\hline & & & $\begin{array}{c}\text { Electrical } \\
\text { GJe }\end{array}$ & $\begin{array}{c}\text { Thermal } \\
\text { GJt }\end{array}$ & & \\
\hline Construction & 31.3 & 1,968 & 709 & 8,180 & - & 10,889 \\
\hline Operation & - & 668 & 1,545 & 14,437 & 29.0 & 16,679 \\
\hline $\mathrm{D} \& \mathrm{D}$ & 31.3 & 1,968 & - & - & - & 1,999 \\
\hline Total & 62.5 & 4,603 & 2,255 & 22,618 & 29.0 & 29,567 \\
\hline
\end{tabular}




\section{A.9 Waste Packages and Surface Storage Casks}

\section{Waste Packages}

The waste packages in this analysis are based on the 21-PWR/44-BWR design that is described in DOERW [2008b]. The waste packages consist of a Transportation, Aging, and Disposal (TAD) canister (stainless steel) surrounded by a two-layer overpack. The overpack includes an inner shell (stainless steel) and an outer shell (a nickel alloy that can be approximated by nickel for energy intensity purposes). Because the TAD can be introduced into the system at the reactor, at interim storage, or at the repository, its energy values are calculated separately on the spreadsheet tool, in a block called Repackaging.

The weight of the TAD canister is estimated from values reported in multiple references. A filled TAD canister has a maximum weight of 54.250 metric tons [DOE-RW 2008b, Section 1.5.1.1.1.2.1.4]. One Pressurized Water Reactor (PWR) fuel assembly has a mass of 0.6579 metric tons [DOE-RW 1997]. If a TAD canister can hold 21 PWR fuel assemblies, the maximum fuel weight in one canister is 13.816 metric tons. By subtracting the maximum fuel mass of one canister from the total mass of a filled TAD canister, an empty PWR TAD canister has a mass of 40.434 metric tons.

The energy associated with constructing the inner canister and outer canister is based on the dimensions of the Transportation, Aging, and Disposal Waste Package reported in DOE-RW [2008b]. The inner shell (with 2 inch thickness, 217 inch outer length, and 71.7 inch outer diameter) is calculated to have a volume of $1.79 \mathrm{~m}^{3}$; when constructed of stainless steel, the mass of the inner shell is 14.018 metric tons. The outer shell (with 1 inch thickness, 223 inch inner length, and 74.08 inch outer diameter) has a calculated volume of $0.98 \mathrm{~m}^{3}$; when constructed of nickel, the mass of the outer shell is 8.725 metric tons.

The required number of waste packages estimated for 140,000 metric tons of spent uranium fuel is based on projections reported in Hardin [2012]. The estimated 209,000 PWR fuel assemblies would be housed in 9,952 waste packages, where 21 assemblies can be held in one waste package. These 9,952 waste packages would hold a total of 91,000 metric tons of spent uranium fuel. The estimated 273,000 BWR fuel assemblies of spent uranium fuel would be housed in 6,205 waste packages, where 44 fuel assemblies can be held in one waste package. These 6,205 waste packages would hold 49,000 metric tons of spent uranium fuel. A total of 16,157 waste packages are required to house 140,000 metric tons of spent uranium fuel. These values are detailed in Table A.9-1.

Table A.9-1. Estimated waste package inventory in a 140,000 MTU commercial spent nuclear fuel repository. These calculations are based on estimates reported in Hardin [2012].

\begin{tabular}{|c|c|c|c|c|}
\hline Туре & $\begin{array}{l}\text { Number of } \\
\text { Assemblies }\end{array}$ & $\begin{array}{c}\text { Assemblies } \\
\text { per Package }\end{array}$ & $\begin{array}{c}\text { Total Initial } \\
\text { Uranium } \\
\text { (MTU) }\end{array}$ & $\begin{array}{c}\text { Number of } \\
\text { Packages }\end{array}$ \\
\hline 21-PWR & 209,000 & 21 & 91,000 & 9,952 \\
\hline 44-BWR & 273,000 & 44 & 49,000 & 6,205 \\
\hline Total & 482,000 & - & 140,000 & 16,157 \\
\hline
\end{tabular}


The energy intensities associated with the materials needed to produce one waste package are represented in Table A.9-2. A total of 5,793 GJ of energy are required to produce one waste package. As described in Table A.9-1, 16,157 waste packages are necessary to properly dispose of 140,000 MT spent uranium fuel. The total energy required for 16,157 waste packages is $73,001,187$ GJ. Using the comparative basis of 1 MT of uranium fuel to remain consistent with this analysis, a total energy of $521 \mathrm{GJ}$ in the form of material inputs is required per MT of uranium fuel.

Table A.9-2. Estimated energy requirements for one waste package. These calculations are based on specifications reported in DOE-RW [2008b] and DOE-RW [1997].

\begin{tabular}{|l|c|c|c|c|c|}
\hline Type & $\begin{array}{c}\text { Volume } \\
\text { per package } \\
\mathbf{m}^{\mathbf{3}}\end{array}$ & Material & $\begin{array}{c}\text { Mass per } \\
\text { package } \\
\text { MT/package }\end{array}$ & $\begin{array}{c}\text { Material } \\
\text { Energy Input } \\
\text { GJ/MT }\end{array}$ & $\begin{array}{c}\text { Final Energy } \\
\text { per Waste Package } \\
\text { GJ/package }\end{array}$ \\
\hline TAD Canister & NR & $\begin{array}{c}\text { Stainless } \\
\text { Steel }\end{array}$ & 40.434 & 56.7 & 2,293 \\
\hline Inner Shell & 1.78 & $\begin{array}{c}\text { Stainless } \\
\text { Steel }\end{array}$ & 14.018 & 56.7 & 795 \\
\hline Outer Shell & 0.98 & Nickel & 8.725 & 164 & 1,431 \\
\hline Total & - & - & $\mathbf{6 3 . 1 7 7}$ & - & $\mathbf{4 5 1 8}$ \\
\hline
\end{tabular}

$* \mathrm{NR}=$ not reported

The energy required for the construction of these 16,157 waste packages is attributed to the construction phase of the waste packages (and the TAD canister repackaging) in the Back-end of the nuclear fuel cycle analyzed in this study. This is shown in Table A.9-3.

Table A.9-3. Energy intensity to construct waste packages and repackage TADs, GJ(e+t)/MT spent uranium fuel.

\begin{tabular}{|l|c|c|c|c|c|}
\hline & & & \multicolumn{2}{|c|}{ Embodied Material } & \multirow{2}{*}{$\begin{array}{c}\text { Total } \\
\text { Phase }\end{array}$} \\
& $\begin{array}{c}\text { Electrical } \\
\text { GJe }\end{array}$ & $\begin{array}{c}\text { Thermal } \\
\text { GJt }\end{array}$ & $\begin{array}{c}\text { Electrical } \\
\text { GJe }\end{array}$ & $\begin{array}{c}\text { Thermal } \\
\text { GJt }\end{array}$ & \\
\hline Construction, TADs & & - & - & 119 & $\mathbf{1 1 9}$ \\
\hline Construction, WPs & - & - & - & 225 & $\mathbf{2 2 5}$ \\
\hline Operation & - & - & - & - & - \\
\hline D\&D & - & - & - & - & - \\
\hline Total & - & - & - & $\mathbf{3 4 4}$ & $\mathbf{3 4 4}$ \\
\hline
\end{tabular}

$\underline{\text { Surface Storage Casks }}$ 
Prior to disposal in a geologic repository, much of the waste stream must be aged either at the utility sites in dry cask storage, or at a centralized interim storage facility. Storage casks will vary in size and construction. For the purposes of this analysis, the surface storage casks are assumed to be a 2-inch-thich carbon steel shell surrounded by a 2-foot-thick concrete shell for radiation shielding purposes.

The energy intensities associated with the materials needed to produce one aging cask are shown in Table A.9-4. A total of 511 GJ of energy are required to produce one aging cask. The number of casks depends on the capacity of the aging facility, which receives input from reactors and sends output to the repository in each year of operation. For this report, the facility capacity is assumed to be 50,000 MT, resulting in 5066 casks, each containing 21 PWR assemblies (or the equivalent mass in smaller BWR assemblies). The total energy required for 5066 aging casks is $2,589,347$ GJ. Dividing by the 140,000 MTU serviced over the lifetime of the aging casks, a total energy of $18.5 \mathrm{GJ}$ in the form of material inputs is required per MT of uranium fuel.

Table A.9-4. Estimated energy requirements to fabricate one Aging Cask.

\begin{tabular}{|l|c|c|c|c|c|}
\hline \multicolumn{1}{|c|}{ Type } & $\begin{array}{c}\text { Volume } \\
\text { per Cask } \\
\mathbf{m}^{\mathbf{3}}\end{array}$ & Material & $\begin{array}{c}\text { Mass per } \\
\text { Cask } \\
\text { MT/cask }\end{array}$ & $\begin{array}{c}\text { Material } \\
\text { Energy Input } \\
\text { GJ/MT }\end{array}$ & $\begin{array}{c}\text { Final Energy per } \\
\text { Cask } \\
\text { GJ/cask }\end{array}$ \\
\hline Inner Shell & 1.80 & Steel & 14.073 & 29.0 & 408 \\
\hline Outer Shell & 35.4 & Concrete & 86.567 & 1.19 & 103 \\
\hline Total & - & - & $\mathbf{1 0 0 . 6}$ & - & $\mathbf{5 1 1}$ \\
\hline
\end{tabular}

The energy required for the production of the 16,157 aging casks is attributed to the construction phase of the aging casks in the Back-end of the nuclear fuel cycle analyzed in this study. Table A.9-5 shows .

Table A.9-5. Energy intensity for aging casks, GJ $(e+t) / M T$ spent uranium fuel.

\begin{tabular}{|c|c|c|c|c|c|}
\hline \multirow[b]{2}{*}{ Phase } & \multirow{2}{*}{$\begin{array}{c}\text { Electrical } \\
\text { GJe }\end{array}$} & \multirow{2}{*}{$\begin{array}{c}\text { Thermal } \\
\text { GJt }\end{array}$} & \multicolumn{2}{|c|}{ Embodied Material } & \multirow{2}{*}{$\begin{array}{c}\text { Total } \\
\text { GJ }\end{array}$} \\
\hline & & & $\begin{array}{c}\text { Electrical } \\
\text { GJe }\end{array}$ & $\begin{array}{c}\text { Thermal } \\
\text { GJt }\end{array}$ & \\
\hline Construction & - & - & - & 18.5 & 18.5 \\
\hline Operation & - & - & - & - & - \\
\hline $\mathrm{D} \& \mathrm{D}$ & - & - & - & 3.7 & 3.7 \\
\hline Total & - & - & - & 22.2 & 22.2 \\
\hline
\end{tabular}




\section{A.10 Geologic Repository and Interim Storage}

\section{Repository}

The calculations in this analysis for a geologic repository of spent nuclear fuel are based on a design reported in the literature [DOE-RW 2008a]. Attributes of that repository design include:

- estimated capacity of 63,000 metric tons of commercial spent nuclear fuel (plus an additional 7,000 metric tons of high level waste),

- estimated capacity 11,629 total waste packages of which 8213 waste packages contain spent nuclear fuel [DOE-RW 2008b], and

- $\quad$ spacing of 5.95 meters between waste packages, measured center-to-center [BSC 2001]

The representative repository used in this Energy Return on (Energy) Investment analysis is expected to differ from the designed repository by an increased spent nuclear fuel capacity of 140,000 metric tons and waste package spacing of 10 meters, measured center-to-center. For subsurface-dominated energy values in this analysis, a scaling factor of 2.64 is used, calculated from:

$$
\frac{140,000 M T S N F_{\text {rep }}}{63,000 M T S N F_{\text {design }}} \times \frac{10 m_{\text {rep }}}{5.95 m_{\text {design }}} \times \frac{8,213 W P_{S N F-\text { design }}}{11,629 W P_{\text {total-design }}}=2.64
$$

For surface-dominated energy values in this analysis, a scaling factor of 1.57 is used, calculated from:

$$
\frac{140,000 M T S N F_{\text {rep }}}{63,000 M T S N F_{\text {design }}} \times \frac{8,213 W P_{S N F-\text { design }}}{11,629 W P_{\text {total-design }}}=1.57
$$

Final energy requirements for a 70,000 metric ton capacity repository including construction, operations, monitoring, and closure are presented in Tables A.10-1 through A.10-3 annually and over the phase duration. Some values are expected to increase if the repository is scaled to hold 140,000 MT spent nuclear fuel; the scaled quantity over the duration of each phase is also reported in these tables. The remainder, such as the materials and the energy resources for the construction of the geologic repository are not expected to increase for a larger facility. In these cases, the scaled quantities are the same as those reported for a 70,000 MT spent nuclear fuel repository.

The quantities of materials and energy resources needed to construct a geologic repository for a capacity of 140,000 MT spent nuclear fuel are shown in Table A.10-1. The duration of the construction phase is estimated to be 5 years, during which the majority of the surface facilities are constructed, with initial subsurface construction including the access ramps and the emplacement drifts and ventilation shafts for the first phase of emplacement. The scaling factor for surface-dominated activities is used. The total energy required for the initial construction of the representative geologic repository is $168 \mathrm{GJ}$ per metric ton of uranium fuel.

The quantities of materials and energy resources needed to operate and monitor a 140,000 MT geologic repository are shown in Table A.10-2. The duration of the operations phase is estimated to be 50 years, during which the remaining surface facilities are constructed, the majority of the subsurface construction occurs, and the emplaced waste packages are ventilated. The scaling factor for subsurface-dominated activities is used. During the monitoring phase, all the emplaced waste packages are ventilated, and performance confirmation activities occur. The scaling factor for surface-dominated activities is used because ventilation and performance confirmation are not sensitive to the empty drift space between 
waste packages. The energy values for operations and monitoring are calculated in the Use-Back sheet of the spreadsheet tool. The total energy required to operate and monitor the representative geologic repository is 3,809 GJ per metric ton of uranium fuel.

Table A.10-1. Energy intensity needed to construct a geologic repository. Copper and steel energy intensities are from Hammond [2008].

\begin{tabular}{|l|c|c|c|c|c|}
\hline Input & Units & $\begin{array}{c}\text { Quantity } \\
\text { per Year }\end{array}$ & $\begin{array}{c}\text { Quantity } \\
\text { over 5 years }\end{array}$ & $\begin{array}{c}\text { Scaled Quantity } \\
\text { over 5 years }\end{array}$ & $\begin{array}{c}\text { Final Scaled Energy } \\
\text { (GJ per MTU fuel) }\end{array}$ \\
\hline Electricity & GWh & 280 & 1,400 & 2,197 & 56.5 \\
\hline Fuel & Gallons & $1,000,000$ & $5,000,000$ & $7,847,240$ & 7.7 \\
\hline Lubricants & Gallons & 138,000 & 690,000 & $1,082,919$ & 1.1 \\
\hline Excavation & $\mathrm{m}^{3}$ & 282,000 & $1,410,000$ & $2,212,922$ & 1.1 \\
\hline Concrete & $\mathrm{m}^{3}$ & 64,000 & 320,000 & 502,223 & 10.5 \\
\hline Copper & $\mathrm{MT}$ & 134 & 670 & 1,052 & 0.5 \\
\hline Steel & $\mathrm{MT}$ & 56,000 & 280,000 & 439,445 & $\mathbf{1 6 8}$ \\
\hline Total & & & & & \\
\hline
\end{tabular}

Table A.10-2. Energy intensity needed to operate and monitor a geologic repository.

\begin{tabular}{|l|c|c|c|c|c|}
\hline Input & Units & $\begin{array}{c}\text { Quantity } \\
\text { per Year }\end{array}$ & $\begin{array}{c}\text { Quantity over } \\
\text { 50 years }\end{array}$ & $\begin{array}{c}\text { Scaled } \\
\text { Quantity over } \\
\text { 50 years }\end{array}$ & $\begin{array}{c}\text { Final Energy } \\
\text { (GJ per MT U } \\
\text { fuel) }\end{array}$ \\
\hline Operations \\
\hline Electricity & GWh & 940 & 47,000 & 123,973 & 3,188 \\
\hline Fuel & Gallons & $3,600,000$ & $180,000,000$ & $474,791,000$ & 463 \\
\hline Lubricants & Gallons & 44,000 & $2,200,000$ & $5,803,001$ & 6 \\
\hline Monitoring & & & & 4,944 & 127 \\
\hline Electricity & GWh & 63 & 3,150 & $21,972,272$ & 21 \\
\hline Fuel & Gallons & 280,000 & $14,000,000$ & $3,766,675$ & 4 \\
\hline Lubricants & Gallons & 48,000 & $2,400,000$ & & $\mathbf{3 , 8 0 9}$ \\
\hline Total
\end{tabular}

The quantities of materials and energy resources needed to close and demolish the140,000 MT geologic repository are shown in Table A.10-3. The duration of the closure phase is 10 years, and it occurs during 
the last 10 years of the monitoring phase. The sub-surface dominated scaling factor is used for electricity and fuel, and the surface-dominated scaling factor is used for concrete removal. The total energy required for repository closure is54 GJ per metric ton of uranium fuel.

Table A.10-3. Energy intensity needed to close a geologic repository.

\begin{tabular}{|l|c|c|c|c|c|}
\hline Input & Units & $\begin{array}{c}\text { Quantity } \\
\text { per Year }\end{array}$ & $\begin{array}{c}\text { Quantity over } \\
\mathbf{1 0} \text { years }\end{array}$ & $\begin{array}{c}\text { Scaled Quantity } \\
\text { over 10 years }\end{array}$ & $\begin{array}{c}\text { Final Energy } \\
\text { (GJ per MT U fuel) }\end{array}$ \\
\hline Electricity & GWh & 72 & 720 & 1,899 & 48.8 \\
\hline Fuel & Gallons & 140,000 & $1,400,000$ & $3,692,819$ & 3.6 \\
\hline Lubricants & Gallons & 53,000 & 530,000 & $1,397,996$ & 1.4 \\
\hline Concrete & $\mathrm{m}^{3}$ & 300 & 3,000 & 4,708 & 0.1 \\
\hline Total & \multicolumn{7}{|r}{} \\
\hline
\end{tabular}

The summary of energies required for the construction, operation, monitoring, and closure of the representative geologic repository are shown in Table A.10-4. The geologic repository is the final destination for spent nuclear fuel in the back-end of the nuclear fuel cycle analyzed in this study.

Table A.10-4. Energy intensity for constructing, operating, and demolishing a geologic repository, per MTU of enriched uranium fuel.

\begin{tabular}{|l|c|c|c|c|}
\hline Phase & $\begin{array}{c}\text { Electrical } \\
\text { GJe }\end{array}$ & $\begin{array}{c}\text { Thermal } \\
\text { GJt }\end{array}$ & $\begin{array}{c}\text { Embodied Material } \\
\text { GJt }\end{array}$ & $\begin{array}{c}\text { Total } \\
\text { GJ }\end{array}$ \\
\hline Construction & 56.5 & 8.7 & 103.1 & $\mathbf{1 6 8}$ \\
\hline Operation & 3,315 & 494 & & $\mathbf{3 , 8 0 9}$ \\
\hline D\&D & 48.8 & 5.0 & 0.1 & $\mathbf{5 4}$ \\
\hline Total & $\mathbf{3 , 4 2 0}$ & $\mathbf{5 0 8}$ & $\mathbf{1 0 3 . 2}$ & $\mathbf{4 , 0 3 1}$ \\
\hline
\end{tabular}

\section{Interim Storage/Aging}

The interim storage facility is the destination for spent nuclear fuel after leaving the nuclear reactor in the back-end of the nuclear fuel cycle analyzed in this study. The surface interim storage facility is assumed to have a capacity of 50,000 MT of spent nuclear fuel per year. The construction energies are assumed to be the same as the repository first five years, scaled by the two facility capacities; this is probably conservative unless repackaging is done at the interim storage facility.

The quantities of materials and energy resources needed to construct an interim storage facility for the aging of spent nuclear fuel are shown in Table A.10-5. The total energy required to construct the interim storage facility is $48 \mathrm{GJ}$ per metric ton of uranium fuel. 
Table A.10-5. Energy intensity needed to construct an interim storage facility.

\begin{tabular}{|l|c|c|c|}
\hline Input & Units & Quantity & $\begin{array}{c}\text { Final Scaled } \\
\text { Energy } \\
\text { (GJ per MT U } \\
\text { fuel) }\end{array}$ \\
\hline Electricity & GWh & 500 & 36.0 \\
\hline Fuel & Gallons & $1,785,714$ & 4.9 \\
\hline Lubricants & Gallons & 246,429 & 0.7 \\
\hline Concrete & $\mathrm{m}^{3}$ & 114,286 & 6.7 \\
\hline \multicolumn{1}{|c|}{ Total } & & & $\mathbf{4 8}$ \\
\hline
\end{tabular}

The energy requirement for the operations phase of the interim storage facility is estimated as $50 \%$ of the repository monitoring values, given the lower level of activity expected for a surface facility and the similar lifetimes. The quantities of materials and energy resources needed to construct an interim storage facility for the aging of spent nuclear fuel are shown in Table A.10-6. The total energy required to operate the interim storage facility is $74 \mathrm{GJ}$ per metric ton of uranium fuel.

Table A.10-6. Energy intensity needed to operate an interim storage facility.

\begin{tabular}{|l|c|c|c|}
\hline Input & Units & Quantity & $\begin{array}{c}\text { Final Scaled } \\
\text { Energy } \\
\text { (GJ per MT U } \\
\text { fuel) }\end{array}$ \\
\hline Electricity & GWh & 1575 & 63.6 \\
\hline Fuel & Gallons & $7,000,000$ & 10.7 \\
\hline \multicolumn{1}{|c|}{ Total } & & & $\mathbf{7 4}$ \\
\hline
\end{tabular}

The quantities of materials and energy resources needed to demolish an interim storage facility are shown in Table A.10-7. The energy requirements for the demolition phase are estimated as $20 \%$ of the energy requirements needed to construct the facility. The total energy required to demolish the representative geologic repository is $9.6 \mathrm{GJ}$ per metric ton of uranium fuel.

The summary of energy required for the construction, operation, and demolition of the interim storage facility is shown in Table A.10-8. 
Table A.10-7. Energy intensity needed to close and demolish an interim storage facility.

\begin{tabular}{|l|c|}
\hline Input & $\begin{array}{c}\text { Final Energy } \\
\text { (GJ per MT U fuel) }\end{array}$ \\
\hline Electricity & 7.2 \\
\hline Fuel & 1.0 \\
\hline Lubricants & 0.1 \\
\hline Foundation Concrete & 1.3 \\
\hline \multicolumn{1}{|c|}{ Total } & $\mathbf{9 . 6}$ \\
\hline
\end{tabular}

Table A.10-8. Energy intensity needed to construct, operate, and demolish an interim storage facility, per MTU of enriched uranium fuel.

\begin{tabular}{|c|c|c|c|c|}
\hline Phase & $\begin{array}{c}\text { Electrical } \\
\text { GJe }\end{array}$ & $\begin{array}{c}\text { Thermal } \\
\text { GJt }\end{array}$ & $\begin{array}{c}\text { Embodied Material } \\
\text { GJt }\end{array}$ & $\begin{array}{c}\text { Total } \\
\text { GJ }\end{array}$ \\
\hline Construction & 36 & 5.6 & 6.7 & 48.2 \\
\hline Operation & 64 & 11 & - & 74.3 \\
\hline D\&D & 7.2 & 1.1 & 1.3 & 9.6 \\
\hline Total & 106.8 & 17.4 & 8.0 & 132.1 \\
\hline
\end{tabular}

